\title{
A“Budding" Cannabis Cottage-Industry has set the stage for an Impending Public Health Crisis
}

\section{Gauvin DV*}

Neurobehavioral Sciences, MPI Research, Mattawan, MI 49071, USA

\begin{abstract}
There is only one legally-competent authority in the United States (US) that can determine what is and what isn't medicine - the Food \& Drug Administration. In 2018, under US and International statutes, marijuana is not medicine. Individual states have approved the cultivation, sale, and distribution of a Schedule I controlled substance in direct violation of International and U.S. drug control statutes. The current administration of the US allows the daily violation and nullification of 3 International United Nation treaties as well as the US Comprehensive Drug Abuse and Control Act (1970). In a search for nirvana, a growing subculture has emerged that has taken the hallucinogen, $\Delta 9$ tetrahydrocannabinol (THC), of the 1960s to "infinity and beyond". Techniques to "boost" or potentiate the actual THC content of marijuana by agricultural refinement, fertilization, and hybrid cultivation of "home grown" or medical advocate suppliers for the "medicinal marijuana" market has dramatically changed the subjective experience of smoked product. More disturbing is the intentional adulteration of bulk harvested materials (spicing), the development of "kitchen-based" extraction techniques (dabbing), and the processes of dose administrations that have grown almost exponentially over the last decade that sets the stage for a new chimera to drug safety in the US. These cottage industries are poised and waiting for national drug control policies to be further weakened to the point of a public health crisis. While legislators debate the drug control issue, a whole subliminal industry has developed in anticipation of free farming of cannabis, with the intent of delivering hybrid dosing of $\mathrm{THC}$ concentrations not believed to be possible just a few years ago.
\end{abstract}

Keywords: Cannabis; Marijuana; High potency; THC; $\Delta 9$ tetrahydrocannabinol; Cannabidiol

\section{Introduction}

This review is intended to sound the public safety alarm regarding the full ramifications of a statutory "end around" to use the legislative branch of government to approve and declare that marijuana is medicine. Medicine is not defined by public vote, community councils, or state legislatures. Under the Food, Drug \& Cosmetic Act, the only legally-competent authority to determine whether any substance is a "medicine" is the executive branch cabinet post position of the Department of Health \& Human Services (DHHS), and through a memo of understanding (MOU), the Commissioner of the Food and Drug Administration. Only after a thorough review of both nonclinical and clinical data it is the FDA alone, that fulfils the legislative mandate to determine what is and what isn't medicine in this country.

A botanical product may be classified as a food (including a dietary supplement), drug (including a biological drug), medical device, or cosmetic under the Federal Food, Drug, and Cosmetic Act (FD\&C Act). Whether an article is a food, drug, medical device, or cosmetic depends in large part on its intended use, though for some product types, other factors must also be considered. (See 21 USC, $\$ 321$ [f][1], [g][1][B] and $[\mathrm{C}],[\mathrm{h}][2]$ and [3], [i], [ff]). A botanical product intended for use in diagnosing, curing, mitigating, or treating disease would meet the definition of a drug under section 201(g)(1)(B) of the FD\&C Act and would be subject to regulation as such. A botanical product intended to prevent disease would also generally meet the definition of a drug under section $201(\mathrm{~g})(1)(B)$ and be regulated as a drug. Under certain circumstances, however, an article that meets the definition of a drug would nevertheless be subject to a different regulatory control scheme.

Because of the heterogeneous nature of a botanical drug and possible uncertainty about its active constituents, one of the critical issues that the FDA is mandated by legal statutes to address is the assurance that the therapeutic effect for each marketed drug product batches are consistent. Each formulation on the market is required to meet strict control standards.
In general, the FDA ensures therapeutic consistency by a "totality of the evidence" approach, including the following considerations:

1) Botanical raw material control (e.g., agricultural practice and collection).

2) Quality control by chemical test(s) (e.g., analytical tests such as spectroscopic and/or chromatographic methods that capture the active or chemical constituents of a botanical drug substance) and,

3) Manufacturing (agricultural) control (e.g., process validation).

4) Biological assay (e.g., a biological assay that reflects the drug's known or intended mechanism of action) and clinical data (for details regarding use of clinical data in ensuring therapeutic consistency.

The federal regulations do acknowledge that botanical drug substances used in various stages of development may differ in some characteristics (e.g., chemical composition), as there could be possible changes in agricultural practice and collection for botanical raw material(s) and/or manufacturing process conditions as a result of process optimization. Therefore, bridging studies may be needed to justify these differences. Under federal statutes it is the cannabis cultivator that must request input from the appropriate FDA review division, so they can evaluate any changes in the botanical drug substance during development and provide guidance (e.g., on the type of bridging studies that may be needed).

*Corresponding author: David V Gauvin, Director, Department of Neurobehaviora Sciences, MPI Research, 54943 North Main Street, Mattawan, MI 49071, USA, Tel: +1 269-668-3336; E-mail: david.gauvin@mpiresearch.com

Received February 05, 2018; Accepted February 13, 2018; Published February 23, 2018

Citation: Gauvin DV (2018) A "Budding" Cannabis Cottage-Industry Has Set the Stage for an Impending Public Health Crisis. Pharmaceut Reg Affairs 7:1. doi: 10.4172/2167-7689.1000199

Copyright: @ 2018 Gauvin DV. This is an open-access article distributed under the terms of the Creative Commons Attribution License, which permits unrestricted use, distribution, and reproduction in any medium, provided the original author and source are credited. 


\section{Pharmacological Effects $\neq$ Therapeutic Efficacy}

The basic foundation for the medical marijuana movement is the search for intoxication. The reality of the legalization of marijuana movement in the US is not fuelled by demonstrative evidence for the use of marijuana, or its' psychoactive elementary components, for the diagnosis, cure, mitigation, or treatment of disease or syndromes affecting man. There are statutory thresholds for the formal adoption of any new molecular entity to be accepted as medicine in the US. Marijuana is not medicine; in 2018 it remains in Schedule I of the Controlled Substances Act [1] as a hallucinogen with no approved medical use in the US.

There are five criteria that define "medical use", all of which must be satisfied:

1. the drug's chemistry must be known and reproducible,

2. there must be adequate safety studies,

3. there must be adequate and well-controlled studies proving efficacy,

4. the drug must be accepted by qualified experts,

5. the scientific evidence must be widely available.

Every state attorneys general in the US that allows access to marijuana is aware that state laws authorizing the use of cannabis for medical purposes and the prevalence of anecdotal reports do not satisfy these federal statutory standards. [cf, DOJ, DEA, Denial of Petition to Initiate Proceedings to Reschedule Marijuana, 21 C.F.R. 40552 at p. 40567 (July 8, 2011)].

Over the last 5 decades a voluminous amount of data has been published in peer-reviewed scientific journals that have yet to provide the requisite foundation for regulatory approval of any new molecular entity submitted to FDA for approval as medicine. In just one federal database, the monetary federal tax dollar support for marijuana research by grants, contracts, and other funding mechanisms used across the National Institutes of Health (NIH) system, as well as disease burden data published by the National Center for Health Statistics (NCHS) at the Centers for Disease Control \& Prevention (CDC) for just the last 3 years (2015 to 2017) was in excess of $\$ 528$ million (https://report.nih. gov/categorical_spending.aspx). In 2015 alone, the National Institutes of Health funded over \$111 million on cannabis/marijuana research, over \$21 million on “cannabinoid research" grants and over \$9 million on funding research on therapeutic cannabinoids [2]. The lack of sufficient, legally-defensible, supportive, valid and reliable data on the therapeutic uses for marijuana components is certainly not the result of lack of funding by the US government.

Dr. Ron Siegel [3] has suggested that throughout our entire history as a species, intoxication has functioned like the basic drives of hunger, thirst, or sex, sometimes overshadowing all other activities in life. Siegel further suggested "intoxication is the fourth drive". Individual and group survival depends on the ability to understand and control this basic motivation to seek out and use intoxicants. The search for intoxication has been an expensive endeavour of the NIH. While one of its Institutions, the National Institute on Drug Abuse (NIDA), has been repeatedly sounding the "general alarm" on the safety, efficacy, and dangers of marijuana, the unbridled access to tax dollars in the US through the NIH grant review committees continue on their accepted mission of "the few funding the few," in a Russia-like oligarchy of federal dollar pay-outs to the search for the alcohol-free "buzz". And all of these money pay-outs thus far show only meagre support for an unstable botanically-based pharmacology with limited comparative therapeutic efficacy.

The Grading of Recommendations, Assessment, Development and Evaluations (GRADE) Working Group, was designed with support from a U34 planning grant from the National Institute of Diabetes and Digestive and Kidney Diseases (NIDDK). GRADE began in the year 2000 as an informal collaboration of people with an interest in addressing the shortcomings of grading systems in health care. It is now widely seen as the most effective method of linking evidencequality evaluations to clinical recommendations. The medical marijuana movement has been built on fallacies. As described by Dr. Robert Dupont, the first administrator of the National Institute on Drug Abuse:

More people need to see "medical marijuana" for what it is: a cynical fraud and a cruel hoax. The conflict being discussed at this hearing today, in my view, is not about medicine; it is about the political exploitation of the public's compassion for suffering sick people. Legitimizing smoked marijuana as a "medicine" is a serious threat to the health and safety of all Americans' [3].

In 2009, the House of Delegates of the Council on Science and Public Health Report of the American Medical Association concluded that

the patchwork of state-based systems that have been established for "medical marijuana" is woefully inadequate in establishing even rudimentary safeguards that normally would be applied to the appropriate clinical use of psychoactive substances [4].

The "grass roots" movement of the state-wide initiatives have duped the public into believing a fallacy of therapeutic efficacy that cannot meet the muster of regulatory medical standards of care or acceptance under the FDA. For illustrative purposes, 3 of the most often cited "therapeutic targets" of cannabis are summarized.

\section{Pain}

The 2001 publication of the Institute of Medicine Report (IOM), that was approved and published by the National Research Council [5], garnered encouragement to marijuana proponents as a tacit approval of the medical community as a whole for the use of the botanical as medicine. The IOM and NRC are not part of the FDA drug approval process and a closer reading of the IOM report would have revealed the tenuous nature of the recommendations for further research on the analgesic properties of the plant. In its review of pain (Chapter 4), the IOM clearly prefaced its standing on the issue:

"some clinical studies not only have failed to demonstrate that THC relieves pain but have also found that the drug has the opposite effect. In these experiments, volunteers who experienced painful shocks, heat, or pressure from a tourniquet reported that THC actually increased their sensitivity to pain (page 79[5])."

Further in reading the chapter, the IOM discussed the findings of contemporary studies by concluding:

"Although they reported feeling less pain, patients who received the highest dose of THC in this study were also heavily sedated. They appeared dreamy and immobile; their thoughts were disorganized, and they described feelings of unreality. Moreover, during the process of selecting patients to participate in the study, five of 36 volunteers became intensely anxious after receiving 10 to 20 milligrams of THC and as a result were excluded from the experiment. If this experiment is any indication, THC's side effects-though somewhat different-are as problematic as those of opiates (page 81 [5])." 
And within a few paragraphs, the IOMs review of the contemporary [49] data on marijuana as an analgesic highlighted the fact that

some patients who appeared calmer after taking THC reported that it had not relieved their pain; other patients said that while their pain remained the same it bothered them less. These impressions resemble several anecdotal reports from marijuana users, who told the IOM team that marijuana did not take away their pain but helped them cope with their discomfort (page 82 [5]).

This summary by the IOM seems to support Ron Siegel's [3] contention for man's search for intoxication not pain relief. The FDA and WHO drug approval processes value scientific integrity, reliability (replicability) and require valid and legally-defensible data. In regulatory agency reviews it's the double-blind, randomized controlled clinical trials having a crossover or parallel design that hold more regulatory weight than "questionnaire-style" studies conducted with small samples of patients conducted in treatment institutions that reside in "pro-marijuana legalization" states. A well-known experimental confound exists in which a subliminal and subjective reactivity in study participants are unintentionally modified such that their behaviour or response is altered by the awareness of being observed within a "promarijuana" environment (Hawthorne Effect). Martin-Sanchez et al. [6] have highlighted the fact that being surrounded by considerable controversy in the media and state-wide policy positions, cannabis has been found to have a marked placebo effect, so that inadequate subject blinding in study protocols would constitute an important source of bias for drug regulators. However, it is clear to all researchers conducting clinical trials with any compound that the characteristic side effects caused by these substances may render perfect subject blinding extremely difficult.

In their 2014 literature review, Brunt et al. [7] concluded that randomized controlled trials of marijuana and its constituent elements have yielded heterogeneous results and have not yet resulted in practical guidelines for the prescription of cannabis for pain.

In their 2016 review of the published literature, Health Canada, the Canadian counterpart to the US FDA, concluded that available evidence comparing patient outcomes following marijuana-based treatments versus placebo appears insufficient to make well-founded conclusions about the clinical advantage and use of these products for the management of chronic neuropathic and non-cancer pain [8].

Deshpande et al. [9], conducted a review of 6 randomized clinical trials investigating therapeutic efficacy of smoked or vaporized marijuana for the treatment of chronic non-cancer pain in 2016. All 6 reports which included 226 patients were reported in peer-reviewed scientific journals [9]. All studies reported statistically significant pain relief with non-serious side effects. While statistical reduction in pain was reported in all studies statistical significance does not always represent a physiologically- or biologically-relevant endpoint. A more fundamental outcome is "clinically-meaningful pain reduction" (a decrease of 2 points on a 0 -to-10 numerical pain rating or a $30 \%$ improvement in pain intensity), which has been associated with an improvement in a patient's global impression of change [10,11]. Only 3 of the 6 studies reported positive findings in this respect. Most of the studies employed marijuana as an adjunct to participants' existing opioids and adjuvant medications, suggesting it might only have a role in refractory pain in conjunction with other more potent opiate analgesics. Generalizing the use of smoked marijuana product to all chronic non-cancer pain conditions were not supported by the existing evidence. The authors concluded that without additional evidence and a clear understanding as to the indications for and dosing of cannabis, there remains a risk that clinicians might unwittingly propagate similar issues that we now face with opioids in the management of non-cancer pain.

Also, in 2017, Bowen \& McRae-Clark [12] reported the results of a comprehensive literature search performed to retrieve randomized controlled trials exploring the efficacy of smoked cannabis for treatment of any medical condition. All studies with the primary endpoint listed as the effect of smoked cannabis on a disease-specific characteristic were included. Open-label studies and studies using other administration methods were excluded. Seven studies met these criteria and were included in the Bowen \& McRae-Clark review. Cannabis did not outperform placebo on experimentally evoked pain. Studies with "quality of life" reported as a secondary outcome measure did not reveal statistically significantly improved outcomes with cannabis use.

In 2017 the US Veterans Administration conducted and reported the results of a literature search and in-depth review of intervention trials and observational studies, published in English, involving adults using plant-based cannabis preparations that reported pain, quality of life, or adverse effect outcomes. The authors did not find strong, consistent or convincing evidence of benefit of cannabis for the treatment of pain. The authors concluded that there is insufficient evidence regarding the effects of cannabis in other patient populations and regarding effects on quality of life and functional status in any population [13,14]. The authors of this 2017 review concluded that virtually no conclusive information exists about the benefits of cannabis in chronic pain populations.

In another recently published report on the analgesic efficacy of adjunctive Sativex ( $\Delta 9$-tetrahydrocannabinol $[27 \mathrm{mg} / \mathrm{mL}$ ]: cannabidiol $[25 \mathrm{mg} / \mathrm{mL}]$ Guy Pharmaceuticals) in advanced cancer patients with chronic pain unalleviated by optimized opioid therapy Fallon et al. [15] reported that Sativex" did not demonstrate superiority to placebo in reducing self-reported pain NRS scores. 303 patients were randomized to Sativex" and 302 to placebo during the parallel-group treatment phases in the two trials. More study "drop-outs" occurred in the cannabinoid treatment group when compared to placebo cohorts. The primary efficacy endpoint (percent improvement (study 1) and mean change (study 2 ) in average daily pain NRS scores) was not met in either study. Subsequent analyses on the per-protocol population, which excluded patients with protocol violations, also found no superiority of Sativex" for the primary endpoints.

To declassify or reschedule marijuana or THC under the Controlled Substances Act the preponderance of timely, valid, reliable, and legally defensible data must support the classification that cannabis is medicine. The most recent reports on the relative analgesic efficacy of marijuana in human clinical trials do not support a claim of medicinal therapeutic advantage and retain the current status that marijuana is not medicine.

\section{Chemotherapy Induced Nausea and Vomiting (CINV)}

One of the leading fallacies of marijuana as medicine relates to its pharmacological effects on appetite and its antiemetic properties. Early proponents of the use of smoked marijuana utilized an "appeal to emotions" fallacy related to patients diagnosed with HIV and experiencing cachexia and loss of appetite. The public and legislative policy makers sympathetically responded to this fallacy with zeal. In 2016, Tafelski, Häuser \& Schäfer [16], reported the results of a comprehensive literature search (through November 2015) conducted in MEDLINE, DARE and Cochrane libraries for systematic reviews of randomized controlled trials (RCTs) comparing herbal or 
pharmaceutical cannabinoids $(\mathrm{CB})$ versus placebo or conventional anti-emetics for CINV. Outcomes were reduction of CINV for efficacy, drop-out rates due to adverse events for tolerability, and serious adverse events for safety. With safe and effective anti-emetics available, the authors concluded that marijuana cannot be recommended as firstor second-line therapy for CINV. The authors also noted that some guidelines recommend pharmaceutical $\mathrm{CBs}$ as third-line treatment in the management of breakthrough nausea and vomiting but due to the lack of RCT data and safety concerns, herbal cannabis cannot be recommended for CINV.

Badowsky [17] recently highlighted the numerous routes of administration that are available for patients with cancer receiving marijuana, including smoking, oral (e.g., cookie, candy, beverages), and mucosal. In contrast with the FDA-approved cannabinoid products (i.e., dronabinol, nabilone), there is a lack of standardization regarding dosing and potency across available home-cultivated marijuana formulations; additionally, the potential for food safety issues cannot be excluded for users of oral products (i.e., foodstuffs, beverages). Badowsky [17] highlights the use of smoked marijuana for therapeutic purposes by patients with cancer has several limitations, including a patient's inability to tolerate smoked product due to taste or the potential for airway obstruction, which may result from inflammation of the airway following smoking. Smoked marijuana may also increase the risk for atrial fibrillation, myocardial infarct, and chronic bronchitis. Further, patients who are immunocompromised may risk additional immunosuppression (e.g., by suppressing lymphocyte proliferation) following use of patient advocate supplied marijuana. In spite of the general consensus that marijuana increases appetite and feeding the therapeutic use of marijuana is currently not recommended by the National Comprehensive Cancer Network (NCCN) for anti-emesis in CINV [18].

\section{Combat-Related Post Traumatic Stress Disorder (PTSD)}

In another targeted use of an "appeal to emotions" fallacy-based argument, pro-marijuana groups have garnered the banner of US veteran organizations to mount a path to approval of marijuana for therapeutic use in combat related PTSD.

In January of 2017 the Canadian Agency for Drugs and Technologies in Health published a review and critical appraisal for the therapeutic use of cannabinoids for the treatment of PTSD [19]. While marijuana is not currently an approved therapeutic product in Canada, the Health Canada website lists PTSD among many conditions in which medical marijuana may be considered of potential therapeutic benefit. In their review there was evidence from very low-quality studies to support the efficacy of smoked marijuana, oral THC, and nabilone in reducing some symptoms of PTSD. The evaluation was unable to identify any relevant evidence-based guidelines regarding the use of medical marijuana for any specific medical conditions. While the findings suggested that smoked marijuana and oral THC are efficacious in treating some symptoms of PTSD, the authors cautioned that the overall GRADE of evidence was very low. Based on these findings and an evaluation of the quality of evidence, the authors concluded that there is very low-quality evidence to support the efficacy of using oral THC or smoked marijuana in treating nightmares and symptom severity in adults with PTSD and in the January 2017 report, Canada Health [19] suggested caution in using medical marijuana for these disorders. In the November 2016 issue of the Journal of Military, Veteran, and Family Health (JMVFH), Sterniczuka \& Whelan [20] reported on cannabis use among Canadian Armed Forces veterans. They concluded that the cannabis users were more likely to use both prescription and non-prescription drugs. No relationships were found between cannabis use and military-related PTSD symptom severity or pain severity. The authors concluded that cannabis use, along with other substance use, is common among Canadian Armed Forces Veterans, and the reasons for cannabis use vary greatly. Cannabis use does not appear to have an impact on PTSDand pain-related symptom expression by these veterans.

The U.S. Veteran's Administration has also published its recent comprehensive evaluation of cannabinoids for the treatment of PTSD in combat veteran's [21] with the same conclusions as the Canadian Health Service. O'Neil et al. [22] conducted a systematic review to assess the benefits and harms of plant-based cannabis use in patients with PTSD as part of a larger report commissioned by the Veterans Health Administration [13]. O'Neil et al., [22] found insufficient evidence to draw conclusions about potential benefits and harms of cannabis use in patients with PTSD. The authors also note that two recent systematic reviews came to similar conclusions, and these reviews, along with 3 additional observational studies, do not provide enough rigorous data to comment on the potential benefits and harms of cannabis use in patients with PTSD. In the 2017 report, the U.S. Veteran's Administration has concluded that virtually no conclusive information exists regarding the benefits of cannabis use in patients with PTSD. (Table 1)

In summary then, in spite of 5 decades of research on the medicinal use of cannabis, there is a paucity of valid and reliable nonclinical and clinical data to demonstrate the efficacy of cannabis that can meet the regulatory requirements to garner "medicine" status under the US FD\&CA. As listed in Table 1, the US Department of Health, the National Institutes of Health's Institute on Drug Abuse (NIDA) and Drug Enforcement Administration has repeatedly conducted the statutory required 8 factor analysis required for schedule control actions to move cannabis into a lower schedule with the same legally defensible, scientifically sound conclusion: "Cannabis has no Medical Use in the United States". As a side note, a report to physicians by Health Canada [23] confirmed their conclusion that the psychoactive / intoxicating effects associated with the use of cannabinoids have been found to limit their therapeutic utility [6,24-27].

\section{This Isn't Your “Grandma’s Ganja” Anymore}

Cannabis is a single genus of annual flowering plants, it belongs to the family Cannabacceae. Many advocates of "medical marijuana" insist on dividing the genus into 3 species: Cannabis sativa, Cannabis indica, and Cannabis ruderalis. All three species can interbreed with the other species. There are both qualitative and quantitative modes of inheritance. According to Hillig [11], qualitative traits are controlled by one or two "major" genes, while quantitative traits are controlled by several "minor" genes, each exhibiting only a small effect. The ratio of THC/CBD is a qualitative trait, and the yield of THC + CBD is quantitative. These are two distinctly different traits, with different modes of inheritance from the same genus.

All of this has little impact to international and national drug control policies, however. Under International and national statutes, that use the Linnean taxonomic classification scheme, there is a single, highly diverse species of the plant Cannabis sativa L. [28]. Under international and federal law:

The term "marihuana" means all parts of the plant Cannabis sativa $L$., whether growing or not; the seeds thereof; the resin extracted from any part of such plant; and every compound, manufacture, salt, derivative, mixture, or preparation of such plant, its seeds or resin. Such term does not include the mature stalks of such plant, fiber produced from such 


\begin{tabular}{|c|c|}
\hline Administrative Action & Source \\
\hline Notice of Denial of Petition to Reschedule Marijuana & [Federal Register: August 18, 2001 (Volume 66, Number 75)] [Notices] [Pages 20038-20076] \\
\hline Interpretation of Listing of "Tetrahydrocannabinols" in Schedule I & $\begin{array}{l}\text { [Federal Register: October 9, } 2001 \text { (Volume 66, Number 195)] [Rules and Regulations] [Page 51529- } \\
\text { 51534] }\end{array}$ \\
\hline Clarification of Listing of "Tetrahydrocannabinols" in Schedule & [Federal Register: October 9, 2001 (Volume 66, Number 195)] [Proposed Rules] [Page 51535-51538] \\
\hline $\begin{array}{l}\text { Exemption From Control of Certain Industrial Products and } \\
\text { Materials Derived From the Cannabis Plant }\end{array}$ & $\begin{array}{l}\text { FR Doc 03-6805 [Federal Register: March 21, } 2003 \text { (Volume 68, Number 55)] [Rules and Regulations] } \\
\text { [Page 14119-14126] }\end{array}$ \\
\hline $\begin{array}{c}\text { Denial of Petition to Reschedule Cannabis, made by Coalition to } \\
\text { Rescheduel Cannabis, NYC, NY }\end{array}$ & June 21, 2011 https://www.deadiversion.usdoj.gov/pubs/coalition_response.pdf\#search=marijuana \\
\hline $\begin{array}{l}\text { Letter from Karen B. DeSalvo, MD, MPH, MSc } \\
\text { Acting Assistant Secretary of Health to Administrator of the DEA }\end{array}$ & 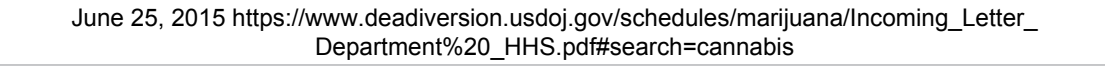 \\
\hline $\begin{array}{l}\text { Schedule of Controlled Substances: Maintaining Marijuana in } \\
\text { Schedule } 1 \text { of the Controled Substances Act }\end{array}$ & $\begin{array}{c}\text { July } 2016 \\
\text { https://www.deadiversion.usdoj.gov/schedules/marijuana/Maintaining\%20Marijuana } \\
\text { \%20in\%20Schedule\%201\%20of\%20the\%20Controlled\%20Substances\%20Act.pdf\#search=cannabis }\end{array}$ \\
\hline $\begin{array}{l}\text { Denial of Petition to Reschedule Cannbis made by The } \\
\text { Honorable Gina M. Raimondo, Governor Rhode Island }\end{array}$ & $\begin{array}{c}\text { August 11, } 2016 \\
\text { https://www.deadiversion.usdoj.gov/schedules/marijuana/Acting_Adminstrator__ } \\
\text { Rosenberg_Response_to_Request_Marijuana_Rescheduling.pdf\#search=marijuana }\end{array}$ \\
\hline $\begin{array}{l}\text { Denial of Petition To Initiate } \\
\text { Proceedings To Reschedule Marijuana }\end{array}$ & $\begin{array}{c}\text { August 12, } 2016 \\
\text { FR Doc DEA-427 } \\
\text { [Federal Register: August 12, } 2016 \\
\text { (Vol. 81, No. 156] } \\
\text { [Proposed Rules] } \\
\text { [Pages 53767-53845] }\end{array}$ \\
\hline
\end{tabular}

Table 1: Administrative Actions/Reviews Relevant to 8 Factor Analyses for Schedule Control Actions on Cannabis: 2001 to 2016.

stalks, oil or cake made from the seeds of such plant, any other compound, manufacture, salt, derivative, mixture, or preparation of such mature stalks (except the resin extracted therefrom), fiber, oil, or cake, or the sterilized seed of such plant which is incapable of germination.

So, regardless of one's personal views of the taxonomic distinction of plant materials that they are cultivating for medical and personal use, all cannabis plant species fall under one single plant category under existing laws (Figure 1).

Breeding of cannabis for use as a drug and medicine, as well as improved cultivation practices, has led to increased potency in the past several decades with median levels of THC in dried female flowers of approximately $21 \%$ by dry weight; levels in some plants exceed $23 \%$. The current heirloom strains of marijuana are Hindu Kush, Pure Afghan, Lambs bread, Durban Poison, Malawi, and Panama Red. From these hybrid stocks a series of cross breeding has created an unlimited number of strains, all with different THC strengths. This process of simple genetic modification of marijuana has cultivated the most potent marijuana in history. The process of growing high potency marijuana is anything but natural. Environmental factors affecting cannabinoid production include day length and nutrient levels. It requires extensive lighting and ventilation systems, staging areas with different temperatures, specific nutrient feed systems, a hypervigilance for inspection for infestations, and specialized harvesting techniques. This breeding effort, largely a covert activity by marijuana growers, has produced hundreds of chemovars (strains) that differ in cannabinoid and terpenoid composition, as well as appearance and growth characteristics - these are considered chemical variations of the same genus.

The THC content of marijuana in the "days of yore" when HaightAshbury (San Francisco, CA) and Woodstock (NY) were in the news (1967 to 1973) was less than 2\% [29]. It has been reported that in man, doses above 1 milligram of THC absorbed by smoking marijuana are sufficient to cause a "high" [30]. Further, Agurell et al. [30] suggested based on mouse data, that a pronounced "high" would be caused by the presence of as little as 10 micrograms of THC in the brain, immediately after smoking a marijuana cigarette. These conclusions, based on a diverse array of pharmacokinetic studies, suggest that low THC-concentrations of marijuana clearly has the capacity to deposit

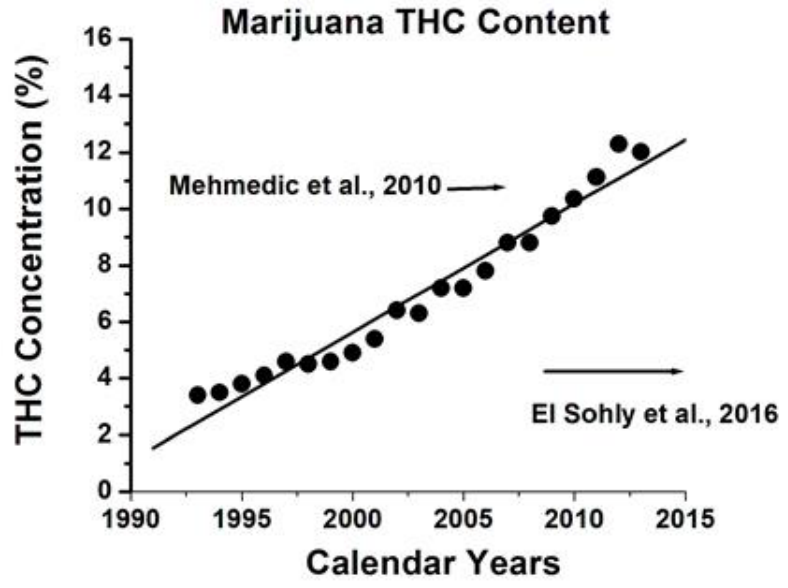

Figure 1: THC concentrations of seized marijuana samples are expressed as a function of time. The data shows the yearly change in the average $\mathrm{THC}$ concentration in retail marijuana analyzed by the laboratories at the University of Mississippi (Ehsohly Labs).

these levels of THC into the brain of man soon after smoking a $1 \%$ THC-containing marijuana cigarette (assuming the typical "joint" of $1 \mathrm{~g}$, with $10 \mathrm{mg}$ THC). THC exerts its most prominent effects on the CNS and the cardiovascular system. Administration of THC via smoked cannabis is associated with decrements in motivation, cognition, judgement, memory, motor coordination, and alterations in perception (especially time perception), sensorium, and mood. Most commonly low potency marijuana produces an increase in well-being and euphoria accompanied by feelings of relaxation and sleepiness. The consequences produced by high potency marijuana or BHO-induced behavioural impairments can greatly impact the public health and safety, given that individuals may be attending school, working, or driving a motor vehicle under the influence of the drug (i.e., marijuana).

Some researchers suggest that cannabidiol (CBD) is the primary constituent element most interesting for medical development and refer to CBD as non-psychoactive. It is the THC content that has been manipulated, guided, or stimulated for one motive - intoxication. 
Scientifically savvy entrepreneurs started a movement to improve the quality of the marijuana stock THC concentrations under the guise of the medical marijuana movement. A "cottage industry" of agricultural, horticultural, plant geneticists [31], and environmental ecologists [32] have developed an information super highway to fuel the quest for the cannabinoid holy grail - the plant with the ultimate THC:CBD concentration ratio of 100:0 [33,34,35]. Conditions of air flow, water exposure, soil quality, cultivar temperatures, and ambient light are detailed in the weighty tomes of the new marijuana library available on easily accessed websites, blogs, and search engines. Books on the agronomy of marijuana are purchased in anonymity and delivered to the door of the cannabis grower by standard commercial web-based service providers. Basement, spare room, or home green-houses have become common in the medical provider programs across the nation. High energy intensive processes used to control environmental conditions during cultivation expose children and adults living within or close to the cultivar to greenhouse gas emissions, volatile organic compound emissions, ozone, pesticides, herbicides, and fungicides. Residential cultivation is substantial in Canada. According to Mills [36] an estimated 17,500 "grow" operations in British Columbia (typically located in residential buildings) are equivalent to $1 \%$ of all dwelling units Province-wide, with an annual market value exceeding $\$ 7$ billion. Official estimates of total U.S. marijuana production varied from 10,000 to 24,000 metric ton per year as of 2001, making it the nation's largest crop by value at that time) [37]. A more recent study estimated national production at far higher levels 69,000 metric ton; [37]. In 2017, the California Council of Land Trusts [38] estimated that there are 50,000 marijuana cultivation sites across California, alone. Although they acknowledged that is a low estimation.

The cottage cannabis industry in collaboration with a popular industry magazine (High Times ${ }^{\mathrm{Tw}}$ ) has established a competition among regional marijuana growers to establish the source of the most potent regional marijuana on the open market [39] (Table 2).
Even at the lower end of this range (chosen as the basis of this analysis), the level of activity is formidable and increasing with the demand for recreational and therapeutic marijuana [36]. Some agronomist believes that the maximal THC content achievable by genetic breeding will "tap out" around 30\%.

The Salmonid Restoration Federation has repeatedly sounded the emergency alarm to the presence of environmental contamination as a result of California's nullification of the federal statutes on marijuana control under the CSA [40]. The energetic popularity of the "green" and environmental movements in California in the 1980's and 90s has given way to passive lethargy, akin to a state-wide motivational syndrome, associated with the free access to a CNS intoxicant through cultivation of marijuana.

As shown in Table 3, links to 24 "warnings" of environmental catastrophes associated with marijuana cultivars can be found on the Salmonid Restoration Federation website (Table 3).

The concern here is NOT about law enforcement or the myth of the "war on drugs". The environmental contaminants related to medical provider-based marijuana cultivation pose a significant health risk to both humans and animals living in close proximity or come in casual exposure to the marijuana growth plots, and also threatens the ecosystem surrounding these outdoor growth plots. Once blanket approval or repeal of existing treaties that bind the US to schedule drug control of marijuana is completed we are set for an environmental disaster as a result of cottage marijuana agribusinesses that have no insight into their own assault on the ecosystems.

Martyny et al. [41] reported on environmental analysis of 30 domestic marijuana grow plots. Samples for airborne fungal spores, volatile organic compounds, carbon dioxide, carbon monoxide, and delta-9-tetrahydrocannabinol (THC) were obtained as well as sample collections for the identification of chemicals utilized in the growth plots. THC levels were identified on surfaces within the homes and on

\begin{tabular}{|c|c|c|c|}
\hline Strain Name & Source of Material & Concentration & Analytical Confirmation \\
\hline \multicolumn{4}{|c|}{ Southern California } \\
\hline Godfather OG & CHR LA Private Reserve & 34.04 & \multirow{5}{*}{ Canna Safe Analytics, Murrieta CA:HPLC } \\
\hline Super Glue & Sun Grower \& Slab Co. & 32.14 & \\
\hline Strawberry Banana & Greenwolf AL \& Green Country Rebellion & 31.62 & \\
\hline Venom OG Kush & Cali Kush Farms \& Greenwolf LA & 31.04 & \\
\hline Redeye OG & Cannabiotix & 29.69 & \\
\hline \multicolumn{4}{|c|}{ Northern California } \\
\hline Boss Frost & Virmutti & 27.5 & \multirow{5}{*}{$\begin{array}{c}\text { Steep Hill Labs } \\
\text { Berkeley, CA: HPLC and QuantaCann2 }{ }^{\mathrm{TM}}\end{array}$} \\
\hline Sour Scout \#1 & IC Collective & 25.2 & \\
\hline Apple Fritter & The Great Indoor Dispensary & 25.2 & \\
\hline Kosher Kush & CannaCruz Collective & 25.0 & \\
\hline Elmer's Glue & Cann Cruz Collective & 24.4 & \\
\hline \multicolumn{4}{|c|}{ Colorado } \\
\hline A-Dub & MMJ America Downtown \& the Vault Genetics & 28.78 & \multirow{5}{*}{ Agricor Laboratories, Denver, CO: HPLC } \\
\hline White Fire OG & Native Roots Colorado & 27.44 & \\
\hline Chem D.O.G. & Next Harvest & 27.04 & \\
\hline Ghost Train Haze & Green Man Cannabis (downtown) & 26.86 & \\
\hline G6 \#3 & Medicine Man & 26.72 & \\
\hline \multicolumn{4}{|c|}{ Michigan } \\
\hline T.C.'s Durban Cookies & Herbal Solutions Ypsilanti/Oasis Medical Seeds & 29.56 & \multirow{5}{*}{ PSI Labs, Ann Arbor, MI (GC/FID) } \\
\hline Motor Breath & Herbal Solutions Ypsilanti & 29.41 & \\
\hline Strawberry Banana & Fly City Meds & 27.8 & \\
\hline $\begin{array}{l}\text { White Fire OG } \\
\text { (aka WiFi OG) }\end{array}$ & MichiganWorkz & 27.68 & \\
\hline Sunshine \#4 & Midnight Roots \& Herbal Solutions & 27.04 & \\
\hline
\end{tabular}

Table 2: Top 5 THC concentrations of bulk marijuana domestic cultivation by regional harvests in the United States (Escondido, 2017). 
How Changing Marijuana Laws May Affect California's Water and Wildlife:

North Coast Regional Water Quality Control Board's Cannabis Cultivation Waste Discharge Regulatory Program.

Environmental Protection Information Center (EPIC) and Mad River Alliance's "2016 Farmer's Compliance Handbook.

Mendocino Resource Conservation District. 2016. "Watershed Best Management Practices for Cannabis Growers and other Rural Gardeners.

Patterson, Brittany. 2015. "California's 50,000 Pot Farms Are Sucking Rivers Dry." Scientific American, 3 July 2015.

Oritz, E. 2013. "Pot grow sites' poisons cited in Fishers' survival struggle." Sacramento Bee, 2013 September 8.

Barringer, F. 2013. "Marijuana crops in California threaten forests and wildlife." New York Times, 20 June 2013

Harkinson, J. 2013. "How industrial pot growers ravage the land: A Google Earth tour." Mother Jones, 6 February 2013

Environ challenges marijuana ag in age of prohibition:

Greenson, T. 2012. "Push for pot regulation; amid federal activity, many still support oversight, regulation of pot industry." The Times Standard, 9 September 2012

Greenson, T. "A 'huge, huge mess;' officials talk environmental impacts of marijuana and the need for more study, clean up." The Times Standard, 9 September, 2012.

Gerken, T. 2012 "Cannabis carbon footprint: Marijuana industry's environmental impact." Huffington Post, 27 August 2012.

Greenson, T. 2013. “'We can't turn a blind eye anymore;' feds, local law enforcement promise 'hot and heavy' season of pot busts." The Times Standard, 26 August 2013.

Burns, R. 2012. "Downy calls for backup: Overwhelmed by marijuana the county sheriff looks to the feds for help." 26 July 2012

M. Mallery. 2010. Marijuana national forests: Encroachment on California public lands for cannabis cultivation. Berkeley Undergraduate Journal, Vol. 23, Issue 2.

UC Davis. 2012. "Poisons of public lands put wildlife at risk".13 July 2012

Gabriel, M. W., L. W. Woods, et al. 2012. Anticoagulant rodenticides on our public and community lands: Spatial distribution of exposure and poisoning of a rare forest carnivore. PLoS ONE, Vol. 7, Issue 7, e40163.

Welsh, J. 2011. "Pot growers destroying national forests." Live Science, 12 December 2011

"Half-baked idea?: Legalizing marijuana will help the environment." Scientific American, 20 May 2011

Service, S. 2010. "Pot: Not so green after all.” PBS, Need to Know, 21 May 2010 Caldwell, A. A. and M. Valdes. 2010. "Public lands sprouting marijuana farms." San Francisco Gate, 14 March 2010.

"Cannabis farming in California using so much water it could wipe out salmon population, biologists warn." The Independenct, 5 October 2014.

Bland, A. 2014. "California's pot farms could leave salmon runs truly smoked." NPR, The Salt, 13 January 2014.

Williams, L., J. Rose, J. Bernard. 2014. "Salmon recovery plan for the Eel River Watershed to examine impact of pot diversions." Willits News, 3 October 2014. https://www.newsdeeply.com/water/articles/2017/03/22/how-changing-marijuanalaws-may-affect-californias-water-and-wildlife

https://www.waterboards.ca.gov/northcoast/water_issues/programs/cannabis/

http://www.wildcalifornia.org/wp-content/uploads/2016/03/Final-ComplianceManual-2-22-16.pdf

http://calsalmon.org/sites/default/files/documents/files/MCRCD Cannabis Watershed_BMP_Guide.pdf

https://www.scientificamerican.com/article/california-s-50-000-pot-farms-aresucking-rivers-dry/

http://snamp.cnr.berkeley.edu/static/documents/2013/09/09/SacBee Pot-growsites-poisons-cited-fishers-survival-struggles.pdf

http://www.nytimes.com/2013/06/21/us/marijuana-crops-in-california-threatenforests-and-wildlife.html?pagewanted=all\& $r=2 \&$

http://www.motherjones.com/food/2013/02/google-earth-tour-marijuana-farmsenvironment-video/

https://vimeopro.com/todu/environ-challenges-of-marijuana-ag-in-the-age-ofprohibition

http://www.times-standard.com/20120909/push-for-pot-regulation-amid-federalactivity-many-still-support-oversight-regulation-of-pot-industry

http://www.times-standard.com/20120902/a-huge-huge-mess-officials-talkenvironmental-impacts-of-marijuana-and-the-need-for-more-study-clean-up

https://www.huffingtonpost.com/2012/08/27/cannabis-carbon-footprintenvironment_n_1832035.htm

http://www.times-standard.com/20120826/we-cant-turn-a-blind-eye-anymorefeds-local-law-enforcement-promise-hot-and-heavy-season-of-pot-busts https://www.northcoastjournal.com/humboldt/downey-calls-for-backup/ Content?oid=2166911

https://escholarship.org/uc/item/7r10t66s\#page-1

https://www.ucdavis.edu/news/poisons-public-lands-put-wildlife-risk-video

http://www.iercecology.org/wp-content/uploads/2012/07/Gabriel_et_al_2012_ PLoSONE_Fisher_Rodenticide.pdf

https://www.livescience.com/17417-marijuana-growers-national-forests.html https://www.scientificamerican.com/article/would-legalizing-pot-be-good-forenvironment/

http://www.pbs.org/wnet/need-to-know/environment/pot-not-so-green-afterall/839/

http://www.sfgate.com/news/article/Public-lands-sprouting-marijuanafarms-3270354.php

http://www.independent.co.uk/news/world/americas/cannabis-farmingin-california-using-so-much-water-it-could-wipe-out-salmon-populationbiologists-9775102.html

https://www.npr.org/sections/thesalt/2014/01/08/260788863/californias-potfarms-could-leave-salmon-runs-truly-smoked

http://www.willitsnews.com/general-news/20141003/salmon-recovery-plan-foreel-river-watershed-to-examine-impact-of-pot-diversions 1

Table 3: Environmental Impacts of Marijuana Cultivation from Salmonid Restoration Federation

the hands of the investigators. A total of 407 fungal spore samples were taken using both slit impactor plates and 400-hole impactors. Both methods identified elevated fungal spore levels, especially during the removal of plants from some of the homes. After plant removal, spore counts increased to levels above 50,000 to over 500,000 spores/cubic meters. While the objectives of the Martyny et al. [41] study was to investigate the health hazards of marijuana cultivars to law enforcement officers who may find themselves conducting a plot eradication of the household, it should be intuitively obvious to most casual reader that chronic daily exposures to these environmental challenges pose a significant health risk to any and all residents of these household medical marijuana cultivars, including their children.

In a study reported by Cone et al. [42], exposure to second-hand smoke from combusted "high potency" cannabis cigarettes (joint) was tested to see if second-hand cannabis smoke might produce a positive drug effect. Cannabis containing 5.3 and $11.3 \%$ THC were used in this study. As shown in Figure 1, above, these represent "common" street marijuana concentrations. According to Cone and colleagues, the amount of THC delivered to the smoker in mainstream smoke from standardized cannabis cigarettes is in the range of $20-37 \%$ of the cigarette content and up to $23-30 \%$ is destroyed by pyrolysis. The remainder, $33-57 \%$ of the original THC, is presumed to be discharged to the environment as smoke and aerosol particles due to side stream smoke, and additional air contamination occurs from mainstream smoke after it is exhaled. "Second-hand" smoke is a combination of these sources. An important finding in the Cone et al. [42] study was the subjective reports of 'pleasant drug effect' by non-smokers exposed to $11.3 \%$ THC-containing cigarette smoke. Cone et al. concluded that the bystander not only experienced a drug effect from passive exposure, but the experience was reported to be a 'pleasant' effect. The authors concluded that extreme exposure of non-smokers could lead to positive drug tests and drug-induced behavioural changes not 
unlike those produced by active cannabis smoking. While these are interesting findings for the street supply of illicit $11.3 \%$ marijuana, it is particularly noteworthy in situations in which a passive non-smoker may be exposed to other smoked products with much higher THC concentrations (in excess of $90 \%$ THC) that are available in other forms of active pharmaceutical ingredient [API] and through other instruments of dosing (see $\mathrm{BHO}$ and vapping, below).

Moosman et al. [43] reported the analytical results of 41 hair samples of children (age: 7 months-12 years) and 35 hair samples of drug consuming parents for the presence of THC-A, THC and cannabinol (CBN). The analytical findings demonstrated that the major part of the cannabinoids detected in the hair samples from the children arose from external contamination through "passive" transfer by contact with contaminated fingers or furniture surfaces and not from inhalation or environmental exposures to side stream smoke. Pichini et al. [44] also analysed the hair of 114 children and found $11.4 \%$ (13 children) had passive exposure to environmental THC. The full impact of these types of environmental exposures to cannabinoids is not yet known. The world as a whole has become an epidemiological study in environmental and developmental toxicology.

\section{Variety is the spice of life: Synthetic Cannabinoids, Spice, K2, and bath salts}

Chemically, the term 'cannabinoid' originally referred to a number of structurally related C21 aromatic hydrocarbon compounds isolated from marijuana. However, following the identification and cloning of the cannabinoid receptors, the term 'cannabinoid' instead came to be associated with drugs exhibiting affinity for the cannabinoid receptors, apart from any structural similarity to compounds originally isolated from the cannabis plant. Therefore, currently accepted nomenclature for 'cannabinoids' are ligands that bind to and modulate the activity of cannabinoids receptors. Today, cannabinoids are structurally diverse and range from compounds that are endogenously produced (endocannabinoids), plant-derived (phytocannabinoids) and synthesized compounds [45].

According to the W.H.O. [46] the synthetic cannabinoids have been defined as:

1. Classical cannabinoids (THC, other constituents of cannabis; and their structurally related synthetic analogues e. g. HU-210, AM-906, AM-411, O-1184)

2. Non-classical cannabinoids (cyclohexylphenols or 3arylcyclohexanols such as CP-47,497-C8, CP- 55,940, CP-55,244)

3. Hybrid cannabinoids (combinations of structural features of classical and non-classical cannabinoids, e. g. AM-4030)

4. Aminoalkylindoles (AAIs), which can be further divided into naphtoylindoles (e. g. JWH-018, JWH-073, JWH-398, JWH-015, JWH-122, JWH-210, JWH-081, JWH-200, WIN-55,212); phenylacetylindoles (e. g. JWH-250, JWH-251); naphthylmethylindoles and benzoylindoles (e. g. pravadoline, AM-694, RSC-4).

5. Eicosanoids (endocannabinoids such as anandamide, and their synthetic analogs like methanandamide)

6. Others, diarylpyrazoles (selective CB1 antagonist Rimonabant ${ }^{\circ}$ ), naphtoylpyrroles (JWH-307), naphthylmethylindenes or derivatives of naphthalene-1-yl- (4-pentyloxy naphthalen-1-yl) methanone (CRA-13).
According to the United Nations Office on Drugs and Crime [46], a creative chemist would be able to easily synthesize hundreds of similar compounds with a high probability of showing cannabimimetic action by the addition of a halogen, alkyl, alkoxy or other substituents to one of the aromatic ring systems. Other small changes such as variation of the length and configuration of the alkyl chain can also be made. In general, syntheses of classical, non-classical or hybrid cannabinoids are much more elaborate and complicated than syntheses of molecules without asymmetric centers like most amino-alkyl-indoles. This is because stereoisomers could show big differences in activity and in some cases the inversion of an asymmetric center could change a receptor agonist into an antagonist. As a result, stereo-selective synthesis or the elaborate separation of stereoisomers is often necessary. Removal of marijuana and/or THC from Schedule I status would set the stage for removal of regulatory controls on these SC's, as well.

It is believed that SCs were first introduced on the designer drug market in several European countries as "herbal incense" before the initial encounter in the United States by U.S. Customs and Border Protection (CBP) in November 2008. From 2009 to the present, misuse and abuse of SCs has increased in the United States as they are applied onto plant material and in designer drug products intended for human consumption (e-cigarrettes, see below). It has been demonstrated that the substances and the associated designer drug products are abused with plant material and on their own for their psychoactive properties.

As detailed by Wiley et al. [47], the synthetic THC drug market had its partial beginnings in the Clemson University laboratory of John W. Huffman, a Harvard graduate, who synthesized novel cannabinoids to investigate targeted receptor sites that may have some use in therapeutics. One of the compounds was named JWH018 which was one of the first synthetic cannabinoids isolated in the European drug market. JWH-018 was structurally an indole amine and not internationally controlled. Clandestine laboratories were creating herbal combination products for sale as incense with "not for human consumption" printed on the outside of each packet. The intent was to provide an alternative hallucinogen to cannabis for people seeking to avoid potential legal consequences of marijuana possession or a "dirty" work drug test. As of this writing there are over 25 controlled SC analogues under the US CSA. If or when a statutory removal of marijuana from schedule 1 of the CSA by Congress is completed, it is highly likely that these 25 SCs will blanket the market and compete with the recreational cannabis growers.

"Spice" is a mix shredded plant material and synthetic cannabinoids that have been sprayed on the plant material to make it look like marijuana. A variety of synthetic cannabinoids have been sold under the names: Smoke, Scence, Yucatan Fire, Skunk, K2, and Spice Gold. The source of material often labels the product "Not for Human Consumption" or calls it "Incense" in an inaccurate belief that such labels protect the clandestine laboratories from prosecution or regulatory control by FDA and/or the DEA. The packaging and retail sources of supply attempt to lead the consumer to believe that they are "natural" and safe. But under the law, "Caveat emptor" which means "let the buyer beware". Similar to the phrase "sold as is," this term implies that the buyer assumes the risk that a product may fail to meet expectations or have defects.

Frank Herbert was a critically acclaimed science fiction author best known for the novel Dune and its five sequels. The Dune saga, dealt with themes such as human survival and evolution, ecology, and the intersection of religion, politics, and power. In the movie series, "spice" was a substance produced by enormous and dangerous sandworms, which bestows special mental qualities on anyone who consumes it. 
A famous quote from the Dune series was: "He who controls the spice controls the universe"

It is not known if the Dune series was the source for the naming of synthetic THC as "spice" but the growth of the underground, black market industry of synthetic THC coincides with the general acceptance of the myth that cannabinoids are generally benign substances. The spice-experience was not solely THC-like. As recently summarized by Ford et al. [45], smoking SCs engenders a myriad of subjective and objectively observed effects that are not part of the generic "marijuana buzz" (see Table 1 of [45]). Seizures, catatonia, self-mutilation, and agitation are "novel" cannabinoid experiences induced by SCs. The experience of catatonia and severe hallucinations under the influence of "spice" may have been reminiscent to the user of the $[48,49]$ psychotomimetic effects of the dissociative anaesthetic, ketamine. These novel subjective effects of SCs may have influenced the nicknaming of spice as "ketamine-2" or "ketamine-junior" which was then sold as "K2" on the streets. The "spice trade" has shown that the man's search for intoxication already poses a significant worldwide public health threat.

The "spice trade" historically refers to the exchange between historical civilizations in Asia, Northeast Africa and Europe. Spices such as cinnamon, cardamom, ginger, and turmeric were known and used in antiquity for commerce in the Eastern World. Today, poised in-the-ready for any changes in marijuana control by federal authorities, there is a clandestine laboratory preferred-provider system of street synthetic cannabinoids already established to provide the new millennials with their search for "spice" on the internet highway. The unregulated supply of synthetic cannabinoids that will occur following the legalization of marijuana poses a significant threat to human health. The health care delivery system will be burdened by the access to synthetic cannabinoids and with the current health service crisis in the US the impending rises in emergency care and dependence intervention clinics will be placed onto the backs of the rank-and-file of employees through higher health insurance costs.

Entropy is a measure of disorder: the higher the disorder, the higher the entropy of the system. Reversible processes do not increase the entropy of the universe. Man's search of the fourth drive, "intoxication" is not easily reversible. The current regulated "closed system" has evolved toward a state of maximum entropy (chaos) where local cities, counties, and state governments believe they have the Constitutional right to repeal federal law. While the legitimate pharmaceutical industry is regulated to high standards in product development, the removal of the regulatory controls established by international treaties ratified by the US Congress and World Health Community (WHO) in regard to the controlled access to cannabis is set to initiate an exponential decline in cannabis market entropy.

\section{To infinity and beyond!}

The cannabis advocates' search for the ultimate state of intoxication has made the cannabis gene pool quite a crowded place to swim. Genetic breeding techniques, cross-breeding, soil control, environmental stability, and agricultural science and technology (S\&T) that promote plant growth and targeting astronomical THC concentrations are deeply rooted in this cottage agro-business which is incompatible with current regulated protection policy environments established by the US Congress that are charged to regulate formal agricultural research and development (R\&D). The genetic and environmental manipulations of home-grown marijuana plots intended to maximize the THC concentrations will soon find the "ceiling effects" or genetic limitations of the core plant material (i.e. approximately $30 \%$, see above).
There are 4 basic preparations of marijuana: bhang, hashish, oil (hash oil), and leaves and/or buds.

1) Bhang is fresh leaves and flowers that have been ground into a paste with a mortar and pestle.

2) Hashish is composed of trichomes from the cannabis plant extracted in a number of different ways and can increase the amount of THC in a given gram up to 8-fold (Gloss, 2015).

3) Hash oil is produced by solvent extraction of plant parts using solvents.

4) leaves and/or flower buds are ingested or smoked.

With that in mind, a cottage industry has emerged focused on the "pharmacological extraction" procedures to concentrate higher and higher levels of THC into hash oil. Hash oil concentrates are made by hydrocarbon solvent application to plant clippings [50]. Liquid butane sold for cigarette lighters or torches is the most common flammable liquid hydrocarbon currently used in this process, however propane, hexane and isopropyl alcohol have also been used. Because of the dangers of explosions with butane, some clandestine laboratories are using charged $\mathrm{CO} 2$ cartridges for the extraction protocol [50].

Butane Hash Oil (BHO) is produced by extracting THC from plant materials using the over-the-counter solvent [51]. During extraction the highly flammable and volatile butane gases permeates the air and be easily ignited through static electricity of any other igniting source (flame, electric spark, etc.) Butane extraction produces THC concentrates that vary in consistency from a waxy substance that looks like cerumen (ear wax) to a brittle substance that looks like thin sheets of hard candy that shatter into small shards of material. In comparison to the THC content in hybridized plant materials described above, $\mathrm{BHO}$ has been demonstrated to be in excess of $60 \%$ THC. BHO has been referred to as wax, dab, crumble, shatter, glass, honeycomb or budder, based on the consistency of the final product [52]. Current production processes of internet-available $\mathrm{BHO}$ contain more than $90 \%$ THC [53].

As shown in Figures 2-4 below, industrious street-wise drug dealers have provided ramped up production of $\mathrm{BHO}$ in a new cottage industry poised to set into motion a wide commercial internet distribution system for the sale of equipment needed for the "super charged" hash oil (Figures 2-4)

Large commercial grade vacuum extracting systems (Figure 2), other components needed for solvent extraction (Figure 3) and gas detection systems to scan environmental butane levels in the area of the extractor are available on common websites. Bell et al. [53] have reported on a surge of hydrocarbon related burns in Colorado and California burn centers that have been linked to the growth of the cottage industry of $\mathrm{BHO}$ production. (Figures 5-7)

The exposure to these relatively astronomical THC concentrations compared to street-based plant materials has already posed a significant health care crisis in emergency departments [1,54-58] which includes hyperemesis syndrome [59], neuro- and cardiotoxicity [60], and psychosis $[51,61,62]$. Davis et al. [63] have reported that since the liberalization of marijuana in Colorado, hospital discharges coded as marijuana-dependence increased 1\% per month from 2007 to 2013.

\section{Vapping: e-cigarette}

The popularity and availability of electronic cigarettes (e-cigs) has given the marijuana smoker a new method of delivery of cannabinoids. The rise in popularity of battery-powered electronic cigarettes, also 


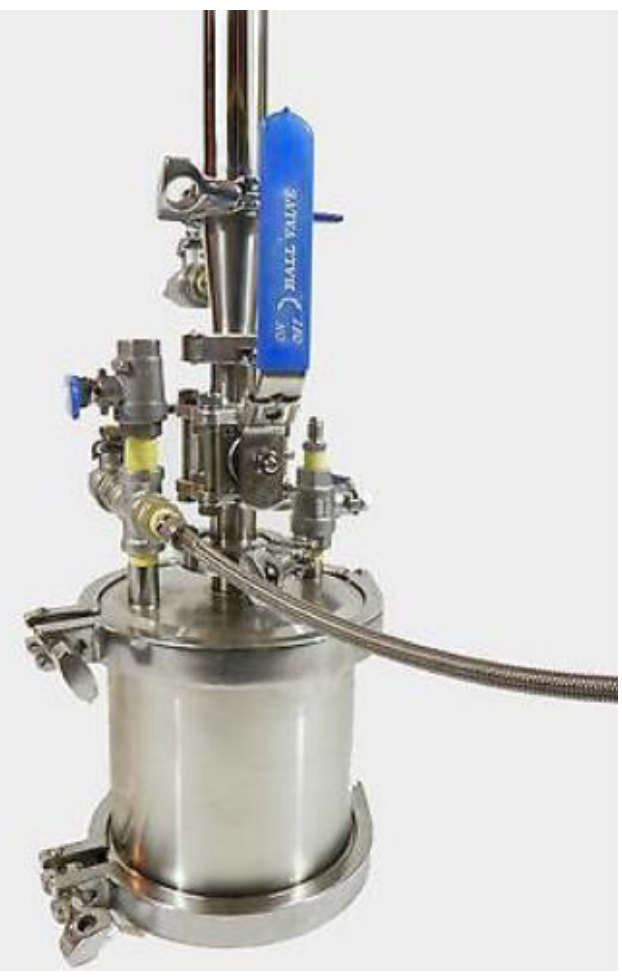

Figure 2: Commercial grade butane extractors are available on the internet that can ramp up kitchen-laboratory production to large scale commercial production.

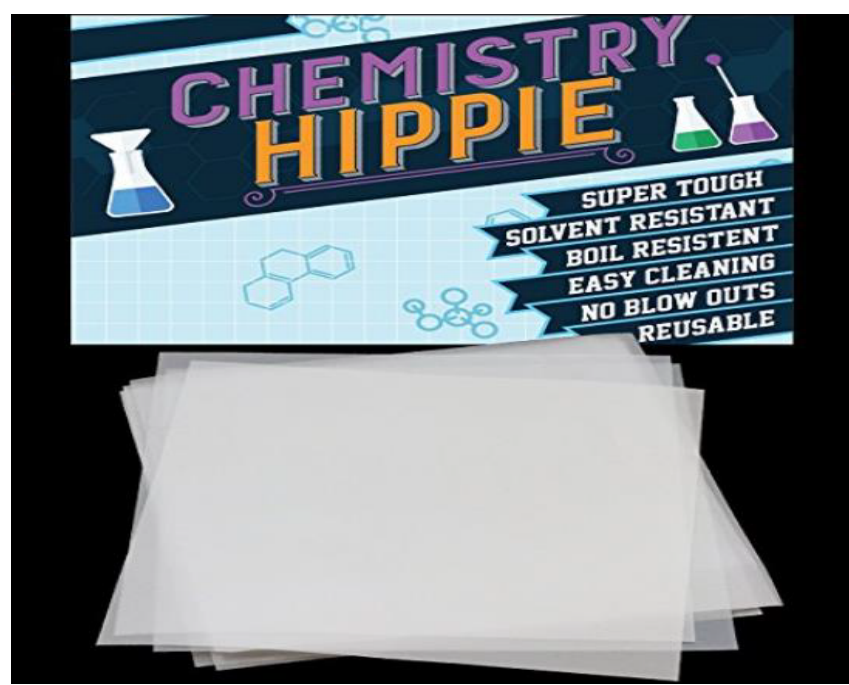

Figure 3: Specialized screens are used in the BHO process that reduces the amount of bulk plant materials from contaminating the final oil product. 25-micron screens are available through commercial lab supply websites.

called personal vaporizers, or electronic nicotine delivery systems (ENDS) in the United States has grown in parallel with the marijuana legalization movement. It is generally assumed that vaporizing cannabinoids at lower temperatures $\left(140^{\circ} \mathrm{F}\right.$ to $\left.374^{\circ} \mathrm{F}\right)$ provides a less toxic delivery of hot combustible products during the burn of a "joint" $\left(1472^{\circ} \mathrm{F}\right.$ to $1652^{\circ} \mathrm{F}$; [64]). Deodorized or perfumed cannabis extracts are now available that mask the smell of marijuana to disguise what is being vaped which decreases the chance of detection. The process is usually referred to as "stealth vaping" [65].

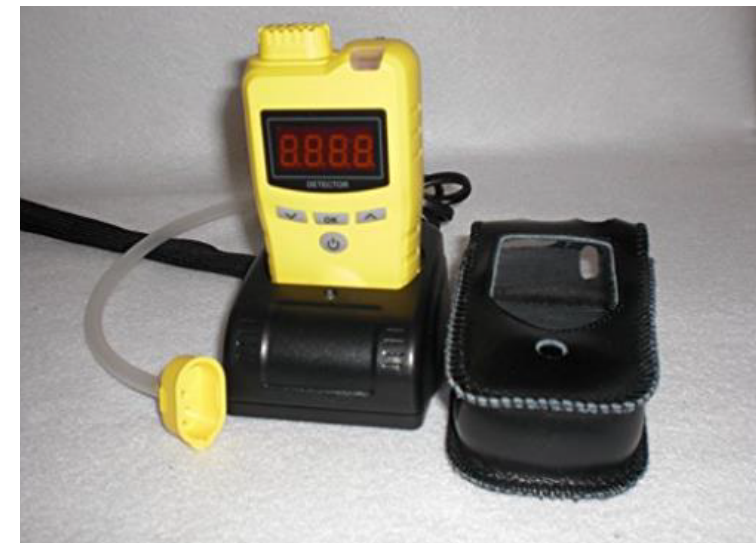

Figure 4: Essential to any clandestine laboratory producing $\mathrm{BHO}$ is the butane detection and alarm system. For sale on common internet sales websites the environmental monitoring of butane concentrations are used because of the high probability of explosions.

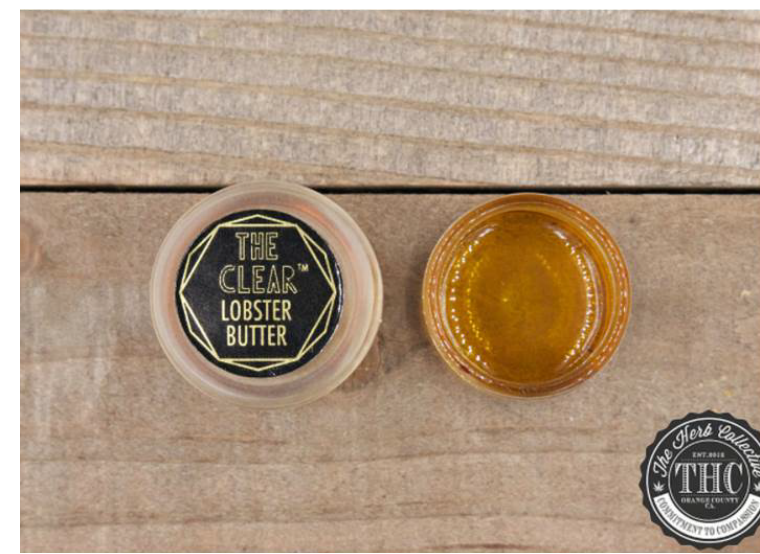

Figure 5: A retail $\mathrm{BHO}$ product available on the internet. "The Clear Concentrate" sells for $\$ 55.00$ per gram and contains $93.62 \%$ THC.

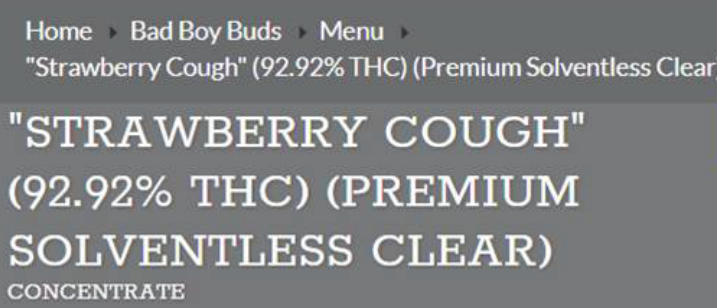

Figure 6: Another commercially available $\mathrm{BHO}$ product named "Strawberry Cough" selling for $\$ 40$ per gram with a THC concentration of $92.9 \%$.

Giroud et al. [66] have confirmed that e-cigs can be used to effectively deliver psychoactive doses of THC. In a detailed analysis of one such e-cig device, Liberty Reach ${ }^{\text {rix }}$, Peace et al. [67] reported that this brand of e-cig delivered $42.6 \% \mathrm{w} / \mathrm{v}$ THC, $0.5 \% \mathrm{w} / \mathrm{v}$ cannabidiol from a retail product advertised to contain $69 \%$ THC and $1 \%$ cannabidiol. Four additional cannabinoids were also found in the pyrolysis product: cannabigerol, cannabichromene, cannabinol, and THC-A; along with 13 marijuana related terpenes: $\alpha$-pinene; $\beta$-myrcene, $\beta$-pinene, limonene, fenchyl alcohol, linalool, terpineol, borneol, $\beta$-caryophyllene, $\alpha$-humulene, guaiol, cedrol and $\alpha$-busabolol. These terpenes are associated with the unique odor and taste of marijuana 


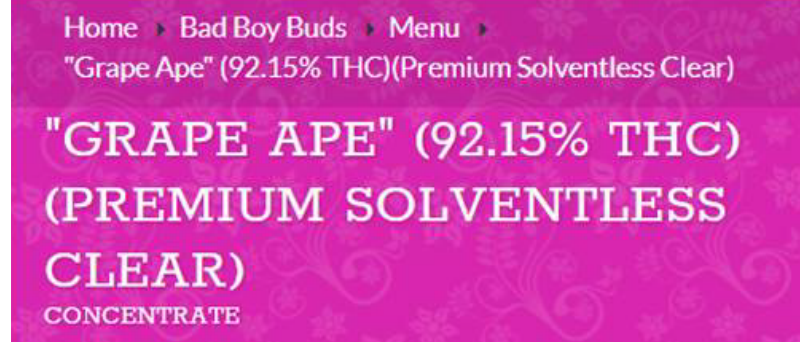

Figure 7: A commercial product named "Grape Ape" is sold on the internet for $\$ 40$ per gram that contains $92.15 \%$ THC by analysis

plant materials and smoke condensates. They are not controlled under the DEA control number for THC (DEA \#7370) but they are controlled as constituent elements of the marijuana plant (DEA \#7360) or marihuana extracts (DEA \#7350).

In a 2014 survey of 3,837 Connecticut high school students Morean et al. [68] reported approximately $18 \%$ of e-cig users and marijuana smokers acknowledge e-cig use for cannabinoid product vapping. $26.5 \%$ of lifetime dual users (both e-cigs and marijuana) reported their use of e-cigs to inhale their cannabis preparations and $15 \%$ of the students reported using e-cigs to vaporize hash oil. A more serious health risk posed by the widespread distribution of e-cigs within adolescent and college aged students is their use to vape other types of psychoactive drugs, such as methamphetamine, cocaine, heroin or bath salts (cathinones). Giroud et al. [66] have also reported that slight modifications to the e-cig has been touted as an efficient method to administer the potent, Schedule I hallucinogen, dimethyltryptamine (DMT).

\section{The Cure May be Worse than the Disease}

Those who consider cannabis benign and support medical marijuana must keep in mind at least 2 additional points: 1) Most data supporting the illusion of drug safety as it pertains to marijuana or THC are based on studies conducted with what we now know as low dose studies (2 to $11 \%$ ). Today commercial supplies are far more potent in psychotogenic content than those early study test articles. 2) There is a paucity of credible scientific data supporting the safety of voluntary consumption of products on the current market containing a range of 30 to $90 \% \mathrm{w} / \mathrm{v}$ THC. The data from earlier low-dose THC materials may no longer be valid.

Although a median lethal dose (LD50) of THC has not been established in humans, it has been found in laboratory animals [21]. In mice, the LD50 for THC was $481.9,454.9$ and $28.6 \mathrm{mg} / \mathrm{kg}$ after oral, intraperitoneal, and intravenous routes of administration. In rats, the LD50 for THC (extracted from marijuana) was 666.0, 372.9 and $42.5 \mathrm{mg} / \mathrm{kg}$ after oral, intraperitoneal, and intravenous routes of administration. Similarly, other studies found that in rats, the LD50 for THC was $1140.0,400.0$ and $20.0 \mathrm{mg} / \mathrm{kg}$ after oral, intraperitoneal, and intravenous routes of administration. There was no LD50 attained in monkeys and dogs by the oral route. Over $3000 \mathrm{mg} / \mathrm{kg}$ of THC was administered without lethality to dogs and monkeys. A dose of about $1000 \mathrm{mg} / \mathrm{kg}$ was the lowest dose that caused death in any animal. Behavioral changes in the survivors included sedation, huddled postures, muscle tremors, hypersensitivity to sound and immobility.

The cause of death in the rats and mice after oral THC was profound depression leading to dyspnea, prostration, weight loss, loss of righting reflex, ataxia, and severe decreases in body temperature leading to cessation of respiration from 10 to 40 hours after a single oral dose. No consistent pathologic changes were observed in any organs. The cause of death in dogs or monkeys (when it rarely occurred) did not appear to be via the same mechanism as in the rats. Thus, the evidence from studies in laboratory animals and human case reports indicates that the lethal dose of THC is quite large. The adverse effects associated with THC use are generally extensions of the CNS effects of the drug and are similar to those reported after administration of marijuana [69-72]. Pierre [73] and Pierre, Gandal and Son [62] reviewed the mounting evidence that the risk of cannabis-induced psychosis may be related to both dose and potency of THC [74] and highlight the increasing reports of psychosis associated with cannabinoids containing greater amounts of THC. Pierre, Gandal \& Son [62] report that "dabbing" with cannabis wax is becoming increasingly popular in the US for both recreational and "medicinal" intentions [74-76], with popular beliefs that it may be safer than smoking $[1,58]$ or that it can even cure cancer. However, the high THC content of BHO raises serious concerns about its psychotic liability. Together with a previous report of cannabisinduced psychosis associated with "medical marijuana" [62,73], the patients use of wax obtained from a dispensary underscores the importance of understanding this risk by physicians recommending cannabinoids for purported medicinal purposes.

THC containing candies such as Gummie Bears, Gummie Worms, and Lollipops are being sold in retail stores. Are the parents in this country to believe these candies are targeting adult consumption or children and adolescents? In a retrospective review of 44 studies, case series, and case reports Richards et al. [77] described the level of intoxication and health consequences of marijuana product ingestion by children. Despite the low absolute numbers of pediatric exposures, Richards concluded that the impact was significant as compared to other childhood exposures [77]. In their opinion of Richards review, Wang and colleagues [78-80] admonished state legislators, public health officials, the marijuana industry, the public and health care providers to take these unintended consequences of legalized marijuana into account when proposing further control actions on the drug.

Andrade [81] conducted a meta-analysis of electronic databases and other available data sources of relevant randomized clinical trials (RCTs) on the use of cannabinoids in for medicinal indications. All comparisons were against placebo and not "standard treatment" yet cannabinoids were not consistently effective for any indication. Data from the Global Burden of Disease Study of 2010 estimated 13.1 million persons were dependent on cannabis. As reported by Andrade [81] cannabis dependence was associated with 2,057,000 years-of-life lived with disability and the same number of disability adjusted lifeyears. Contained ingredients in medical marijuana products run into the hundreds and issues related to pharmacology and drug interactions are poorly understood. The potency and balance of the contained active ingredients vary, making precise dosing impossible. As admonished by Andrade [82] advocates of medical marijuana who proclaim that any association with adverse outcomes in the study data does not prove cause should well consider that if cannabis were to be proposed as a prescription drug by the pharmaceutical industry, the wealth of evidence of adverse outcomes associated with it would provoke social activists, human rights advocates, lawyers and the mass media into a feeding frenzy of outrage. State legislators, popular votes and community sentiment does not make it safe OR effective.

\section{State sponsored terrorism to the public health system}

In a December 2016 Forbes article, Debra Borchardt [83] reported a projected $700 \%$ growth in the cannabis market by the year 2020 . Presenters at the Cannabis World Congress \& Business Expo held on 
June 17, 2016 in New York City, estimated that the CBD market had the potential to grow to a $\$ 2.1$ billion market in consumer sales by 2020 with $\$ 450$ million of those sales coming from marijuana-based sources. Borchardt [83] also reported that in 2015, the market for consumer sales of marijuana-derived CBD products was $\$ 90$ million, plus another $\$ 112$ million in marijuana-derived CBD products which were sold through dispensaries - bringing a total CBD market to \$202 million in 2015, alone. The NYC financial research team, GreenWave Advisors, seems even more optimistic about the growth of the CBD market. As quoted by Borchardt in the Forbes article, Green Wave estimates an almost $\$ 3$ billion market by 2021 [83] (Figure 8).

One consequence to public health from the rising THC concentrations available in domestically grown cannabis is the identification of a cannabis hyperemesis syndrome. Cannabinoid hyperemesis syndrome (CHS) is a recently reported syndrome of cyclic vomiting associated with cannabis use. According to Sorensen et al. [84] a common medical history of patients includes regular cannabis for any duration of time (100\%), cyclic nausea and vomiting (100\%), resolution of symptoms after stopping cannabis (96.8\%), compulsive hot baths with symptom relief (92.3\%), male predominance $(72.9 \%)$, abdominal pain (85.1\%), and at least weekly cannabis use $(97.4 \%)$. The pathophysiology of CHS remains unclear. In 2008, Koob and Le Moal [61] extended the "opponent process theory" [85] of motivation
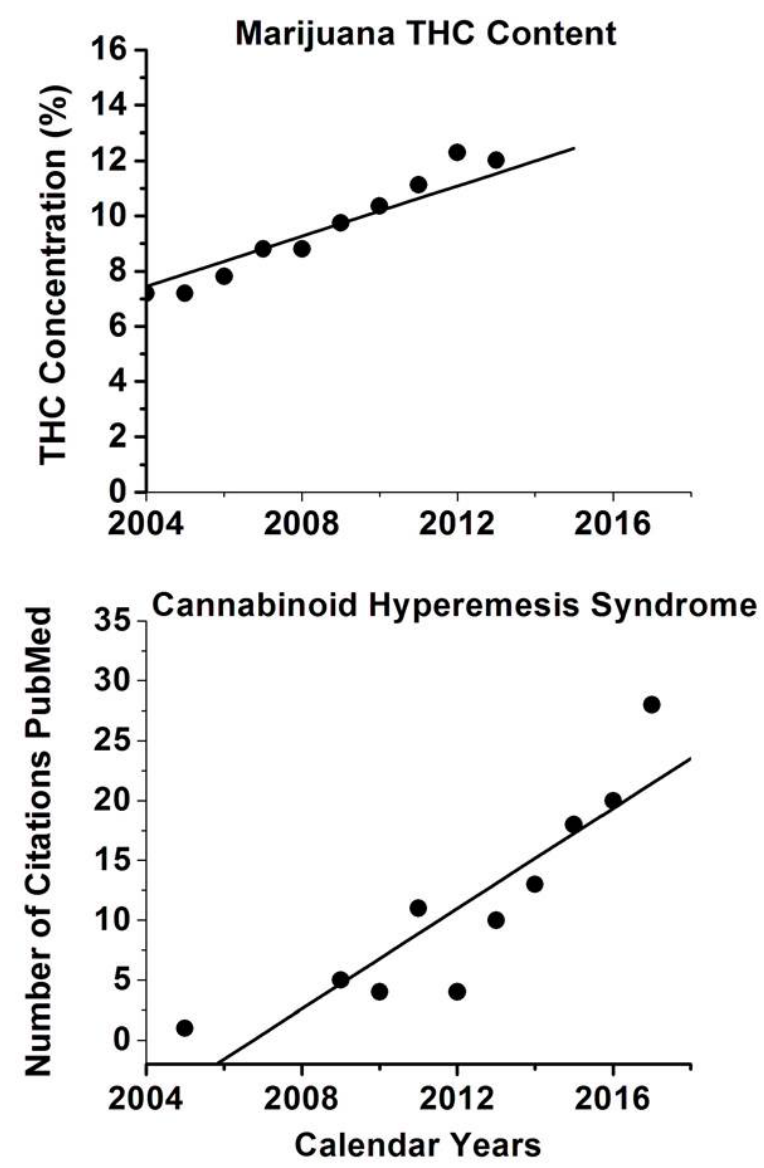

Figure 8: Top Panel- The grand mean THC concentrations of retail marijuana quantified at the University of Mississippi plotted as a function of time. Bottom Panel- The number of published reports per year appearing in the National Library of Medicine's PubMed data base under search terms "cannabis" and "hyperemesis syndrome". to explain the cyclic changes in physiological responses to drug administration (Figure 2) [61]. Addiction is seen as a repetitive cycle of drug-like and drug-opposite effects that serve to motivate the drug user to continue the repetitive nature of the disorder. "Hangover", an acute withdrawal reaction, is a classic example of the acute opponent process of excessive ethyl alcohol intake. It is well known that cannabis induces the motivation to eat in normal street users - this was the motivation to ineffectively use marijuana to encourage eating in chemotherapyinduced cachexia. The opponent physiological state of the "munchies" may well be the hyperemesis syndrome that is being seen in emergency departments nationwide. The acute withdrawal from high THC potency marijuana may induce this compensatory hyperemesis syndrome that was not seen with street sources of lower THC concentration marijuana that were most common just a few years ago. Richards, Lapoint \& BurilloPutze [77] have proposed that CHS may result from a derangement in the endogenous cannabinoid system secondary to chronic intake of high potency marijuana. The unique nature of the CHS is that the patient reports relief of nausea and vomiting through hot baths and emergency room reports a relief by the topical administration of capsaicin. The relief of CHS symptoms from heat and use of capsaicin, a transient receptor potential vanilloid-1 agonist, suggests a complex interrelation between the endogenous cannabinoid system and transient receptor potential vanilloid-1 receptor complex. According to Richards, Lapoint and Burillo-Putze [77] hot water hydrotherapy is a mainstay of self-treatment for CHS patients (hot baths). This may be explained by heat-induced transient receptor potential vanilloid-1 activation. Transient receptor potential vanilloid-1 activation by heat or capsaicin results in modulation of tachykinins, somatostatin, pituitary adenylate-cyclase activating polypeptide, and calcitonin generelated peptide as well as histaminergic, cholinergic, and serotonergic transmission. These same neurotransmitter systems are involved in the expression of opiate withdrawal syndromes. These downstream effects represent further possible explanations for transient receptor potential vanilloid-associated antiemesis associated with the new domestically grown marijuana.

A second threat to public health associated with state-sponsored nullification of federal statutes and international treaty commitments is the presence of agricultural/ industrial contaminants in cultivated marijuana. As discussed by Gauvin [74], main health risks come from pesticide residues on plants, cultivation infrastructure and materials; left-over plant growth-promoting substances; mycotoxins from fungal pathogens on harvested plants; and/or high levels of cannabinoids in cannabis plant parts for consumption. In 2016, 22 out of 26 marijuana samples were positive when analyzed for pesticide contamination in cultivation plots from the State of Washington (USA). Many harboured multiple contaminants attaining levels 10 's of thousands of parts per billion (ppb) and exceeding the upper limit of quantitation for the analytical system used for the analyses. The contaminants included 45 distinct agents from every class of insecticides, miticides, fungicides, synergists and growth regulators, including organophosphates and organochlorides. As cited by Gauvin [86] a 2017 report identified pesticides found in indoor cannabis plantations in Belgium. In that study, $64.3 \%$ of 72 cannabis plant samples and in $65.2 \%$ of 46 carbon filter cloth samples taken from the air supply of the fruticetum. Overall, 19 pesticides belonging to different chemical classes were identified, including o-phenylphenol, bifenazate, cypermethrin, imidacloprid, propamocarb, propiconazole and tebuconazole, which are consistent with the commonly reported pesticides in the literature. In only a few cases, pesticides found in bottles with a commercial label, were also identified in plant or stagnant water samples collected from the growth rooms where the bottles had been collected. Further revealed 
was the fact that, even though most pesticides have a low volatility, they could be detected from the carbon filters hanging at the ceiling of cultivation rooms. As a result, it is likely that pesticides also prevail in the plantation atmosphere during and after cultivation. The risk of inhaling the latter pesticides increases when plants sprayed with pesticides are intensively manipulated during dismantling activities. As cited by Gauvin [86] California grown patient-advocate grown marijuana were submitted by the end users requesting analysis for contaminants. Thirty-three percent of all submitted samples were found to be contaminated with pesticides. The most commonly found pesticide in the California samples was paclobutrazol, a plant growth regulator. This is of great concern because this pesticide is not registered by the U.S. Environmental Protection Agency (EPA) for use on food crops since up to $70 \%$ of paclobutrazol is transferred into the smoke stream. Two other pesticides found in the US samples were bifenthrin (a pyrathroid insecticide) and myclobutanil (a systemic fungicide). In 2015, myclobutanil was found in Colorado-grown marijuana by the Colorado Department of Agriculture $[87,88]$. In the health alert it was noted that the Colorado Department of Agriculture had identified and published a list of "minimum risk pesticides" that pose little or no risk to human health and are allowable for use on marijuana during cultivation. The myclobutanil is not on this list, but the absence of regulatory oversight has contributed to its widespread use in marijuana cultivation in Colorado. These data strongly support the conclusion that state-sponsored agricultural processes that allow pesticides into the botanical consumption market pose an underestimated and underdocumented health risk for the marijuana user. With respect to the fictitious "medical marijuana" market these pesticides were potentially administered to admittedly sick patients - sponsored by the states of Colorado, California, and Washington.

On September 17, 2017 the distinguished statesman from Utah, Senator Orin Hatch, introduced the Marijuana Effective Drug Study Act of 2017, or MEDS Act, to improve the process for conducting scientific research on marijuana as a safe and effective medical treatment. He was joined by Senator Schatz (D-HI) and cosponsors Senator Chris Coons (D-DE), Senator Cory Gardner (R-CO), and Senator Thom Tillis (RNC) in submitting the bill. In his "call to arms" Senator Hatch stated, "we need to remove the administrative barriers preventing legitimate research into medical marijuana, which is why I've decided to roll out the MEDS Act".

While the worldwide pharmaceutical industry is bound to a standardized drug application process with drug regulatory control and oversight, these Senators, are calling for the exception to these standards for the unique botanical "wonder drug" marijuana.

Under its current version The MEDS Act will:

1) Remove schedule control status of marijuana when used in research in direct violation of International Drug Control Treaties and the Comprehensive Drug Abuse and Control Act enacted by the US Congress in 1970.

2) Require the National Institute on Drug Abuse (NIDA) to develop and publish recommendations for good manufacturing practices for growing and producing marijuana for research. The Senators must be aware that the NIDA under the general National Institutes of Health falls under the executive cabinet post of the Secretary of Health. NIDA is not a law enforcement agency under the US Constitution. NIDA is a research institute, not a regulatory agency. Under the constitution NIDA is not charged to initiate laws, guidelines, or administrative policies germane to agricultural growth, environmental protection, pesticide use (EPA) or regulate food, botanical, and medicinal products (FDA).

3) MEDS Act calls for the termination of the Public Health Service and its review of proposals for medical research on marijuana. It calls for actions to prevent the Department of Health and Human Services from instituting any other marijuana-specific protocol reviews, other than the voluntary review that a researcher can request from National Institutes of Health (NIH) in order to access the expedited DEA registration process.

These Senators have been misinformed. They have not been briefed on the critically relevant literature published in peer reviewed scientific journals. These Senators have missed the mark of "doing their homework".

The current climate of subliminal threats to public health imposed by the current legalization movement with respect to:

1) genetic manipulations of plant materials,

2) the sky-rocketing concentrations of the major psychoactive entity (THC) with diminished concentrations of CBD in existing marijuana plants,

3) the cottage industry focusing on THC extractions (BHO) supplying toxic concentrations of $>60 \%$ THC to patients, and

4) the cottage industry developing new and improved medical devices to ensure maximal dose-per-puff THC administrations, should activate the proverbial Emergency Broadcast System nationwide.

These four critical issues, combined with the voluminous data now showing the lack of any significant therapeutic efficacy of either THC or CBD using standardized pharmaceutical grading methodologies argues against the approval of the MEDS Act.

\section{Conclusion}

We are on the brink of a national health crisis with respect to the current state-initiated policies on marijuana. The Constitution of the US guarantees life and the pursuit of happiness of its citizens. The same Constitution provides for the public defence of enemies foreign and domestic. The health and welfare of citizens guaranteed by the US Constitution are being threatened by the unbridled and unregulated marijuana production agro-business. Cottage industries have developed that are poised to flood the market with dangerously high and potent THC in marijuana and its by-products under the banner of "medical marijuana". Pandora's box has been opened by state initiatives in direct violation of federal statutes and International Drug Control Treaties. Congress is mandated to serve the public welfare, not to provide avenues for major escalations in health care costs that are on the horizon as a result of acute toxicity, unexpected poisoning (psychosis, hyperemesis syndromes, etc.), development of dependence, and clinical depression resulting from same. Worldwide scientific drug development is a rigorous process - it has to be. Regulatory agencies have adopted a universal set of stringent requirements to be fulfilled before drugs are approved for marketing (International Committee on Drug Harmonisation). These safeguards are necessary to protect public welfare. According to Andrade [82] the current safety and efficacy data for medical marijuana fall well short of these standards.

Good manufacturing practices (GMP) cannot be applied to botanicals. There is no legitimate control of concentrations or concentration ratios for each botanical harvest. There is absolutely no credible evidence of genetic stability, genetic drift is the norm. In 
1974 through 1976 the University of Mississippi cultivated 7 variants of 12 Cannabis plants discovered and collected in 1973 from different areas of Mexico. Cannabinoid content was analyzed weekly during the cultivation period. Turner et al. [88] summarized their findings as follows:

In 1974, vegetative plants of $M E-H, M E-K, M E-L, M E-N$ and $M E-$ $O$, at 13 weeks of age had higher $\triangle 9$-THC content that at weeks 12 and 14. They showed minimum $\triangle 9-T H C$ content at week 15 . For the most part, 1974 staminate and pistillate plants grown in Mississippi produced a low $\triangle 9-T H C$ concentration.....In all variants, the average $\triangle 9-T H C$ was higher in 1976 than in 1974. Also, a greater fluctuation of $\triangle 9-T H C$ was observed in 1976 than in 1974.

These results further establish that Cannabis Sativa L. is not a stable hybrid plant, but rather, represents characteristics more similar to an unstable weed. A closer examination of one of the variants planted by Turner et al. [88], may further clarify this point. Turner and colleagues measured the THC concentrations for several weeks of growing during the 1974 and 1976 cultivation period for pistillate and staminate plants of the ME- $\mathrm{H}$ variant of the study. The $\mathrm{ME}-\mathrm{H}$ variant originated from Poza Rica, Veracruz, Mexico in 1973. Their data revealed that the THC concentration and the total cannabinoid content of these plants not only varied over weeks of cultivation, but also that they increased from first to the second generation of growth within the same cultivation plots.

In addition to public health risks, and as described above, the current growth plots pose a significant burden on the eco-system. A well-programmed shell-game has been played out in the media and social networks. While arguing drug safety the marijuana advocates have been subliminally developing a cottage industry focusing on the delivery of high potency THC products that contain levels of THC that were not believed to be possible just a decade ago. The pharmaceutical industry as a whole should take control of the reins of the cannabinoid therapeutic market. There should not be a double standard for new drugs coming to market by legitimate pharmaceutical development programs and the raw botanical products touted as safe and effective. Natural product does not mean safe product. Financial support of pharmaceutical companies to congressional and presidential campaigns should be tightly restricted to those who jeopardize the public health of the US and provide for a discretionary, biased, and prejudicial relaxation of standards of research for drug approval.

\section{References}

1. Stogner JM, Miller BL (2015) The dabbing dilemma: A call for research on butane hash oil and other alternate forms of cannabis use. Subst Abus 36 : 393-395.

2. National Institute on Drug Abuse (NIDA) (2017) NIH Research on Marijuana and Cannabinoids. USA.

3. Siegel RK (2005) Intoxication: The Universal Drive for Mind-Altering Substances. Rochester, VT: Park Street Press.

4. The Council on Science and Public Health. Use of Cannabis for Medicinal Purposes.

5. Mack A, Joy J (2001) Marijuana As Medicine?: The Science Beyond the Controversy. National Academy Press, Washington, D.C., USA

6. Martin-Sanchez E, Furukawa TA, Taylor J, Martin JL (2009) Systematic review and meta-analysis of cannabis treatment for chronic pain. Pain Med 10: 1353 1368

7. Brunt TM, van Genugten M, Höner-Snoeken K, van de Velde MJ, Niesink RJ (2014) Therapeutic satisfaction and subjective effects of different strains of pharmaceutical-grade cannabis. J Clin Psychopharmacol 34: 344-349.

8. Canadian Agency for drugs and Technologies in health (2016) Cannabinoid Buccal Spray for Chronic Non-Cancer or Neuropathic Pain: A Review of Clinical
Effectiveness, Safety, and Guidelines. Canada.

9. Deshpande A, Mailis-Gagnon A, Zoheiry N, Lakha SF (2015) Efficacy and adverse effects of medical marijuana for chronic noncancer pain: Systematic review of randomized controlled trials. Can Fam Physic 61: e372-e381.

10. Dworkin RH, Turk DC, Wyrwich KW, Beaton D, Cleeland CS, et al. (2008) Interpreting the clinical importance of treatment outcomes in chronic pain clinical trials: IMMPACT recommendations. J Pain 9: 105-121.

11. Hillig K (2002) Letter to the Editor. J Indust Hemp 7: 5-6.

12. Bowen LL, McRae-Clark AL (2018) Therapeutic Benefit of Smoked Cannabis in Randomized Placebo-Controlled Studies. Pharmacotherapy. 38: 80-85.

13. Kansagara D, O'Neil M, Nugent S, Freeman M, Low A, et al. (2016) Benefits and harms of cannabis in chronic pain or post-traumatic stress disorder: A systematic review. VA ESP Project no. 05-225. Washington, DC: U.S Department of Veterans Affairs.

14. Nugent SM, Morasco BJ, O'Neil MJE, Freeman M, Low A, et al. (2017) The effects of cannabis among adults with chronic pain and an overview of general harms: A systematic review. Ann Intern Med 167: 319-331.

15. Fallon MT, Lux EA, McQuade R, Rossetti S, Sanchez R et al. (2017) Sativex oromucosal spray as adjunctive therapy in advanced cancer patients with chronic pain unalleviated by optimized opioid therapy: two double-blind, randomized, placebo-controlled phase 3 studies. Br J Pain 11: 119-133.

16. Tafelski S, Häuser W, Schäfer M (2016) of systematic Efficacy, tolerability and safety of cannabinoids for chemotherapy-induced nausea and vomiting--a systematic review of systematic reviews. Schmerz 30: 14-24.

17. Badowsky ME (2017) A review of oral cannabinoids and medical marijuana for the treatment of chemotherapy induced nausea and vomiting: a focus on pharmacokinetic variability and pharmacodynamics. Cancer Chemother Pharmacol. 80: 441-449.

18. https://www.nccn.org/professionals/physician_gls/default.aspx

19. Canadian Agency for Drugs and Technologies in Health (2017) Medical Marijuana for Post-Traumatic Stress Disorder: A Review of Clinical Effectiveness and Guidelines. Rapid Response Report: Summary with Critical Appraisal.

20. Sterniczuka R, Whelan J (2016) Cannabis use among Canadian Armed Forces Veterans. J Milit Vet Fam HIth 2: 43

21. Phillips RN, Turk RF, Forney RB (1971) Acute toxicity of delta-9tetrahydrocannabinol in rats and mice. Proc Soc Exper Biol Med 136: 260-263.

22. O'Neil ME, Nugent SM, Morasco BJ, Freeman M, Low A, et al. (2017) Benefits and harms of plant-based cannabis for posttraumatic stress disorder: $A$ systematic review. Annal Intern Med 167: 332-340.

23. Information for Health Care Professionals (2013) Cannabis (marihuana, marijuana) and the cannabinoids. Controlled Substances and Tobacco Directorate at Health Canada, Canada.

24. Guindon J, Lai Y, Takacs SM, Bradshaw HB, Hohmann HG (2012) Alterations in endocannabinoid tone following chemotherapy-induced peripheral neuropathy: Effects of endocannabinoid deactivation inhibitors targeting fatty-acid amide hydrolase and monoacylglycerol lipase in comparison to reference analgesics following cisplatin treatment. Pharmacol.Res 67: 94-109.

25. Kalliomäki J, Philipp A, Baxendale J, Annas P, Karlsten R, et al. (2012) Lack of effect of central nervous system-active doses of nabilone on capsaicin-induced pain and hyperalgesia. Clin Exp Pharmacol Physiol 39: 336-342.

26. Kraft B (2012) Is there any clinically relevant cannabinoid-induced analgesia? Pharmacology 89: 237-246.

27. Wallace M, Schulteis G, Atkinson JH, Wolfson T, Lazzaretto D, et al. (2007) Dose-dependent effects of smoked cannabis on capsaicin-induced pain and hyperalgesia in healthy volunteers. Anesthesiology, 107: 785-796

28. EISohly MA, Radwan MM, Gui W, Chandra S, Galal A (2017) Phytochemistry of Cannabis sativa L. Prog Chem Organ Nat Prod 103: 1-36.

29. Wilkinson ST, Yarnell S, Radhakrishnan R, Ball SA, D'Souza DC (2016) Marijuana legalization: impact on physicians and Public Health. Annu Rev Med 67: 453-466.

30. Agurell S, Halldin M, Lindgren JE, Ohlsson A, Widman M, et al. (1986) Pharmacokinetics and metabolism of delta-1-tetrahydrocannabinoid and othe cannabinoids with emphasis on man. Pharmacol Rev. 38: 21-43. 
31. Rosenthal E (2010) Marijuana Grower's Handbook. Quick American Publishing: Oakland, CA.

32. Rosenthal E (2012) Marijuana Pest and disease control. Quick American Publishing: Oakland, CA.

33. http://www.growweedeasy.com/increase-the-potency-growing-weed

34. https://howtogrowmarijuana.com/5-ways-increase-the-growing

35. http://www.vice.com/en us/article/8gk4zb/marijuana-growers-are-upping-thethc-ante-with-super-potent-pot-456

36. Mills $E$ (2012) The carbon footprint of indoor cannabis production. Energy Policy 46: 58-67.

37. Gettman J (2006) Marijuana Production in the United States. The Bulletin of Cannabis Reform, December 2006.

38. California Council of Land Trusts (2017) Report from the California Council of Land Trusts: Environmental Impacts of Illegal Marijuana Cultivation. Conservation frontiers 6

39. http://hightimes.com/grow/the-strongest-strains-on-earth-2017

40. Salmonid Restoration Federation. Environmental Impacts of Marijuana Cultivation.

41. Martyny JW, Serrano KA, Schaeffer JW, Van Dyke MV (2013) Potentia Exposures Associated with Indoor Marijuana Growing Operations. J Occup Environ Hyg 10: 622-639.

42. Cone EJ, Bigelow GE, Herrmann ES, Mitchell JM, LoDico C, et al. (2015) Nonsmoker Exposure to Second hand Cannabis Smoke III. Oral Fluid and Blood Drug Concentrations and Corresponding Subjective Effects. J Anal Toxicol 39: 497-509.

43. Moosmann B, Roth N, Hastedt H, Jacobsen-Bauer A, Pragst F, et al. (2013) O2: Cannabinoid findings in children hair - what do they really tell us? Toxicol Anal Clin 26: S5

44. Pichini S, García-Algar O, Alvarez A-T, Mercadal M, Mortali C, et al. (2014) Pediatric exposure to drugs of abuse by hair testing: monitoring 15 years of evolution in spain. Int J Environ Res Public HIth 11: 8267-8275.

45. Ford BM, Tai S, Fantegrossi WE, Prather PL (2017) Synthetic Pot: Not Your Grandfather's Marijuana. Trends Pharmacol Sci 38: 257-276.

46. World Health Organization (2011) Synthetic cannabinoids in herbal products United Nations Office on Drugs and Crime.

47. Wiley JL, Marusich JA, Huffman JW, Balster RL, Thomas BF (2011) Hijacking of basic research: the case of synthetic cannabinoids. Meth rep, RTI Press.

48. Muetzelfeldt L, Kamboj SK, Rees H, Taylor J, Morgan CJ (2008) Journey through the K-hole: phenomenological aspects of ketamine use. Drug Alcohol Depend 95: 219-229.

49. Stirling J, McCoy L (2010) Quantifying the psychological effects of ketamine: from euphoria to the K-Hole. Subst Use Misuse 45: 2428-2443.

50. Graves K (2016) Butane hash oil investigations: An investigative guide for law enforcement. Graves \& Associates, LLC: Brentwood, CA, USA.

51. Raber JC, Elzinga S, Kaplan C (2015) Understanding dabs: contamination concerns of cannabis concentrates and cannabinoid transfer during the act of dabbing. J Toxicol Sci 40: 797-803.

52. Meier MH (2017) Association between butane hash oil use and cannabisrelated problems. Drug Alcohol Depend 179: 25-31.

53. Gollick J (2016) Shifting the paradigm: Adolescent cannabis abuse and the need for early intervention. J Psychoactive Drugs 48: 24-27.

54. Loflin M, Earleywine M (2014) A new method of cannabis ingestion: the danger of dabs? Addict Behav 39: 1430-1433.

55. Miller BL, Stogner JM, Miller JM (2016) Exploring butane hash oil use: A research note. J Psychoactive Drugs 48: 44-49.

56. Romanowski KS, Barsun A, Kwan P, Teo EH, Palmieri TL, et al. (2017) Butane hash oil burns: A 7-year perspective on a growing problem. J Burn Care Res 38: e165-e171.

57. Miller BL, Stogner JM, Miller JM (2016) Exploring butane hash oil use: A research note. J Psychoactive Drugs 48: 44-49.
58. Gammeter WB, Duke KA, Soundy TJ (2016) Case report of intractable vomiting and abdominal pain related to heavy daily cannabis use. SD Med Spec No: 60-63.

59. Romano LL, Hazekamp A (2013) Cannabis oil: chemical evaluation of an upcoming cannabis-based medicine. Cannabinoids 1: 1-11.

60. Koob GF, Le Moal M (2008) Neurobiological mechanisms for opponent motivational processes in addiction. Phil Trans R Soc B 363: 3113-3123.

61. Pierre JM, Gandal M, Son M (2016) Cannabis-induced psychosis associated with high potency "wax dabs". Schizo Res 172: 211-212.

62. Davis JM, Mendelson B, Berkes JJ, Suleta K, Corsi KF, et al. (2016) Public health effects of medical marijuana legalization in Colorado. Am J Prev Med 50: 373-379.

63. Davis JM, Mendelson B, Berkes JJ, Suleta K, Corsi KF et al. (2016) Public health effects of medical marijuana legalization in Colorado. Am J Prev Med 50: $373-379$

64. Earlywine M, Barnwell SS (2007) Decreased respiratory symptoms in cannabis users who vaporize. Harm Reduct J 4: 11

65. https://vaporizer-info.com/en/vaporizing-cannabis

66. Giroud C, de Cesare M, Berthet A, Varlet V, Concha-Lozano N, et al. (2015) E-cigarettes: A review of new trends in cannabis use. Int J Environ Res Public Health 12: 9988-10008.

67. Peace MR, Stone JW, Poklis JL, Turner JBM, Poklis A (2016) Analysis of commercial marijuana e-cigarette formulation. J Analyt Tox 40: 374-378.

68. Morean ME, Kong G, Camenga DR, Cavallo DA, Krishnan-Sarin S (2015) High school students' use of electronic cigarettes to vaporize cannabis. Pediatrics 136: 611-616

69. Chait LD, Evans SM, Grant KA, Kamien JB, Johanson CE, et al. (1988) Discriminative stimulus and subjective effects of smoked marijuana in humans. Psychopharmacology. 94: 206-212.

70. Chait LD, Zacny JP (1992) Reinforcing and subjective effects of oral $\Delta 9$-THC and smoked marijuana in humans. Psychopharmacology. 107: 255-262.

71. Cone EJ, Johnson RE, Paul BD, Mell LD, Mitchell J (1988) Marijuana-laced brownies: Behavioral effects, physiological effects and urinalysis in humans following ingestion. J Anal Toxicol. 12: 169-175.

72. Pertwee RG (1991) Tolerance to and dependence on psychotropic cannabinoids. in: the biological bases of drug tolerance and dependence. Academic press: New York 231-263.

73. Pierre JM (2010) Psychosis associated with medical marijuana: risk vs. benefits of medicinal cannabis use. Am J Psychiatry 167: 598-599.

74. Moore THM, Zammit S, Lingford-Hughes A, Barnes TRE, Jones PB, et al. (2007) Cannabis use and risk of psychotic or affective mental health outcomes: A systematic review. Lancet. 370: 319-328.

75. Daniulaityte R, Nahhas RW, Wijeratne S, Carlson RG, Lamy FR, et al. (2015) "Time for dabs": Analysing Twitter data on marijuana concentrates across the U.S. Drug Alcohol Depend. 155: 307-311.

76. Krauss MJ, Sowles SJ, Mylvaganam S, Zewdie K, Bierut LJ, et al. (2015) Displays of dabbing marijuana extracts on YouTube. Drug Alcohol Depend 155: 145-151.

77. Richards JR, Lapoint JM, Burillo-Putze G (2018) Cannabinoid hyperemesis syndrome: potential mechanisms for the benefit of capsaicin and hot water hydrotherapy in treatment. Clin Toxicol (Phila) 56:15-24.

78. Wang GS, Heard K, Roosevelt G (2017) The unintended consequences of marijuana legalization. J Pediatr 190: 12-13

79. Wang GS, Roosevelt G, Heard K (2013) Pediatric marijuana exposures in a medical marijuana state. JAMA Pediatr 167: 630-633.

80. Wang GS, Roosevelt G, Le Lait MC, Martinez EM, Bucher-Bartelson B, et al. (2014) Association of unintentional pediatric exposures with decriminalization of marijuana in the United States. Ann Emerg Med 63: 684-689.

81. Andrande C (2016) Cannabis and neuropsychiatry, 2: The longitudinal risk of psychosis as an adverse outcome. J Clin Psychiatry. 77: e739-e42.

82. Andrande C (2016) Cannabis and neuropsychiatry, 1: Benefits and Risks. J Clin Psychiatry 77: e551-e554. 
83. Borchardt D (2016) The cannabis market that could grow $700 \%$ by 2020 . Forbes.

84. Sorensen CJ, DeSanto K, Borgelt L, Phillips KT, Monte AA (2017) Cannabinoid Hyperemesis Syndrome: Diagnosis, Pathophysiology, and Treatment-a Systematic Review. J Med Tox 13: 71-87.

85. Solomon RL, Corbit JD (1974) An opponent-process theory of motivation: Temporal dynamics of affect. Psychol Rev 81: 119-145.
86. Gauvin DV (2017) A Plant is NOT Medicine: Plant vs. Constituent Element. Pharm Regul Aff 6: 196.

87. EISohly MA, Radwan MM, Gui W, Chandra S, Galal A (2017) Phytochemistry of Cannabis sativa L. Prog Chem Organ Nat Prod 103: 1-36.

88. Frank C, Cindy Blair (2016) Eagle 20 and Myclobutanil in the Context of Cannabis Cultivation and Consumption. Colorado Green Lab 2: 1-4. 